\title{
Al servicio de una ciudad en expansión. Casimiro Meseguer Bonet, Director de Caminos del ayuntamiento de Valencia (1874-1914)
}

\author{
At the service of an expanding city. Casimiro Meseguer Bonet, \\ Director of Roads for Valencia City Council (1874-1914)
}

\author{
Alfredo Faus Prieto ${ }^{1}$ (i)
}

\section{Resumen}

Casimiro Meseguer Bonet ocupó el cargo de Director de Caminos del ayuntamiento de Valencia entre 1874 y 1914. El ejercicio de este empleo le convirtió en uno de los principales protagonistas de la gran transformación urbanística que experimentó la ciudad a partir de 1865, coincidiendo con el derribo de sus murallas medievales. Como principal responsable de la composición, el mantenimiento y la alineación de los caminos y las sendas extramuros, en su despacho se proyectaron los ejes viarios que permitieron la anexión de los poblados próximos y la materialización de los ensanches aprobados en 1887 y 1912. En este artículo se realiza una síntesis de la carrera profesional de Casimiro Meseguer Bonet, en la que se incluyen su etapa inicial como Ayudante de Obras Públicas (1866-1874) y las principales actuaciones que llevó a cabo desde la Dirección de Caminos de la ciudad de Valencia (1874-1914).

Palabras clave: Ciudad de Valencia; Dirección de Caminos; Casimiro Meseguer Bonet; Carrera Profesional.

\begin{abstract}
Casimiro Meseguer Bonet was director of roads at Valencia City Council between 1874 and 1914. The exercise of this role turned him into one of the main protagonists of the great urban transformation that the city experienced, coinciding with the demolition of its medieval walls from 1865 . He was responsible for the composition, maintenance, and alignment of roads and trails outside the city walls, and in his office were projected the road axes that enabled the annexation of nearby towns and the widenings approved in 1887 and 1912. This article offers a synthesis of the professional career of Casimiro Meseguer Bonet, which includes its initial stage as a public works assistant (1866-1874) and the main actions he took as director of roads for the City of Valencia (1874-1914).
\end{abstract}

Keywords: City of Valencia; director of roads; Casimiro Meseguer Bonet; professional career.

\section{Introducción}

El interés por la evolución urbanística de las ciudades españolas, y en especial de la ciudad burguesa de la segunda mitad del siglo XIX, de larga tradición en el colectivo de geógrafos (Terán, 1996; 1999), parece haberse reactivado en los últimos años (Fernández, 2011; Mendoza, 2011a y 2011b; y Cardesín y Mirás, 2014). El examen pormenorizado de las áreas de expansión decimonónica ha devenido un tema de investigación prioritario dado que, en última instancia, sobre ellas se configuraron las ciudades extensas

1 Doctor en Geografía. alfredo.faus@uv.es 
actuales (Delgado, 2016). Existe acuerdo en torno a los objetivos fundamentales que debe atender este tipo de estudios: el crecimiento físico de las ciudades sobre su entorno inmediato; la construcción de las infraestructuras y los servicios públicos que llevaba aparejado dicho crecimiento; y la creación, la organización y las actuaciones concretas de las instituciones que lo dirigieron. Se trata de una investigación compleja, en la que confluyen todos los aspectos que fueron identificados hace tiempo como los propios de un análisis geográfico del medio urbano: la incorporación de nuevos terrenos a la ciudad, la alteración de sus límites históricos, los cambios que afectaron a la propiedad, el valor y los usos del suelo, y la estructura funcional del nuevo núcleo (Straszewicz, 1981).

Tal complejidad obliga a tratar esta realidad desde una visión multidisciplinar, amplia y diversa, que constituya un punto de encuentro entre la Geografía y otras ciencias sociales afines. Entre ellas se encuentra la Historia, ya que al necesario enfoque espacial debe unírsele el componente temporal que implica todo proceso de cambio. Los trabajos sobre los orígenes del planeamiento urbanístico son indispensables para entender las ciudades contemporáneas, en particular si tratan de la influencia que sobre las decisiones tomadas tuvo la personalidad de los responsables políticos que lo diseñaron y los técnicos que lo ejecutaron, así como el impacto futuro de estas decisiones (Miño, 2003; Capel, 2009a y 2009b). Es en esta dirección en la que cobra gran importancia la investigación sobre los organismos que dirigieron el proceso de cambio y el perfil de los profesionales que los integraban. En la España de la segunda mitad del siglo XIX que ahora nos interesa, los autores de esta planificación fueron los negociados municipales de Policía Urbana y Rural que se extendieron por todo el país (Anguita, 1997; 2001). Su estudio enriquece cualquier aproximación al fenómeno urbano que tenga vocación holística.

En el caso de la ciudad de Valencia, aunque hay auténticos clásicos escritos desde el campo de la Geografía (Sanchis Guarner, 1972; Teixidor, 1982), los mejores trabajos sobre la transformación urbanística que sufrió en la transición entre los siglos XIX y XX se deben a un grupo selecto de arquitectos. Décadas de investigaciones pueden verse resumidas en la monumental Historia de la Ciudad, dirigida por Francisco Taberner (2000-2016). Las actuaciones previas a los planes de ensanche, su desarrollo concreto, la transformación de barrios enteros como consecuencia de la especulación, los grandes proyectos de reforma interior, etc., han sido analizados en multitud de artículos y libros. Sin embargo, desde la precursora obra de Daniel Benito sobre la arquitectura valenciana del eclecticismo (Benito, 1983), la atención de estos investigadores se ha dirigido casi en exclusiva hacia los arquitectos que encabezaron las iniciativas que cambiaron la imagen de la ciudad (Joaquín $\mathrm{M}^{a}$ Arnau, los hermanos Calvo, José $\mathrm{M}^{a}$ Manuel Cortina, Luis Ferreres, Sebastián Monleón, etc.). Hasta seis de ellos han merecido estudios biográficos en los últimos años (Arnau, Peiró y Poyatos, 2008; Arnau, 2011; Casao y García, 2009; Jaime, 2013; Arbaiza, 2014; y Cabrera, 2015). De manera sistemática, en estos estudios se ha dejado de lado a los colaboradores que estos arquitectos tuvieron en las secciones municipales de Policía Urbana y Ensanche (sobrestantes, delineantes, escribientes, maestros de obra, etc.).

De entre los cargos adscritos a otros negociados del ayuntamiento de Valencia que coadyuvaron con estas secciones sobresalen los de Director de Caminos, Director de Paseos, Arboledas y Jardines, e Ingeniero Municipal. Nuestro protagonista, Casimiro Meseguer Bonet (Sueca, 1841-Valencia, 1915)², ocupó el primero de ellos durante cuarenta años (1874-1914). En ese tiempo, como encargado de la red de caminos extramuros, facilitó la extensión física de la ciudad y, en gran medida, redibujó los tentáculos que la hicieron posible. En su despacho se planificaron las grandes avenidas creadas sobre los caminos y las sendas preexistentes, las nuevas rondas de circunvalación y multitud de calles y plazas surgidas de la alineación de los caminos que unían Valencia con los pueblos próximos que iría anexionando, los que llevaban desde estos pueblos al mar o los que vertebraban la huerta y la conectaban con los mercados urbanos. Una tarea hercúlea, alejada de los focos, que se solapó en el tiempo con la que desarrollaron los arquitectos que firmaron los planes de ensanche y reforma interior.

A pesar de la trascendencia de estas actuaciones, la figura de Casimiro Meseguer sigue estando asociada exclusivamente al proyecto que debía unir la ciudad con su frente marítimo: el Paseo desde la plaza del Jardín del Real hasta el Pueblo Nuevo del Mar que dio lugar a la actual avenida de Vicente Blasco Ibáñez. Poco importa que este proyecto, presentado en 1888, pudiera haberse inspirado en una idea anterior del arquitecto Manuel Sorní o que el inicio de su ejecución se demorase hasta 1926, con nuestro

2 Casimiro Meseguer Bonet nació el 11 de marzo de 1841 en Sueca (Valencia). Archivo Histórico Municipal de Sueca: Registro Civil, 1841-1843. Signatura SEC-00330/001 
protagonista ya fallecido. El nombre de Casimiro Meseguer constituye una cita obligada, todavía hoy, en todos los estudios sobre la evolución decimonónica de la ciudad de Valencia y en todos los dictámenes generados por las discusiones políticas en torno a la conveniencia o la inconveniencia de prolongar el paseo hasta el mar a través del caserío edificado del barrio del Cabañal-Cañamelar.

$\mathrm{Y}$, sin embargo, este proyecto sólo fue una de las muchas iniciativas que Casimiro Meseguer emprendió desde la Dirección de Caminos del ayuntamiento de Valencia. De hecho, hubo al menos otros tres proyectos que le granjearon un prestigio aún mayor en vida: la finalización del paseo de la Alameda y su conexión con el camino Nuevo del Grao, la instalación de vías metálicas en este mismo camino para facilitar la circulación de carruajes hacia y desde el puerto, y la construcción del camino de Tránsitos de Consumos en sus tres secciones $\left(1^{\mathrm{a}}, 2^{\mathrm{a}}\right.$ y Norte). La segunda de estas iniciativas le procuró, incluso, fama nacional e internacional. En el momento de su formulación mereció dos entradas en la Revista de Obras Públicas que la popularizaron entre los profesionales del sector (Sanchis, 1896 y 1897) y un par de reseñas recogieron, años más tarde, su extensión a otros caminos de la ciudad (Anónimo, 1910; Settier, 1912).

El resto de los grandes proyectos mencionados sigue esperando un estudio de detalle que le haga justicia: del papel decisivo de Casimiro Meseguer en la reforma del paseo de la Alameda apenas se han escrito unas líneas que datan del siglo pasado (Santamaría, 1988; Gavara, 1994); los trabajos disponibles sobre el camino-paseo de Valencia al Mar sólo lo mencionan para sembrar dudas sobre la originalidad de su idea y reducir la importancia de su impacto urbanístico (Piñón, 1988 y 2000; Boira, 2000); del origen del camino de Tránsitos de Consumos, nada se sabe. No es objetivo de este artículo abordar semejante reto. Sí lo es avanzar un extracto de la dilatada carrera profesional de Casimiro Meseguer en el que cobren sentido semejantes iniciativas. A partir de fuentes de archivo, se intenta mostrar su formación como Ayudante de Obras Públicas y cómo su trabajo para el ayuntamiento de Valencia, desarrollado a lo largo de cuarenta años, fue crucial en el proceso de creación de la ciudad extensa que hoy compartimos.

\section{Metodología}

\subsection{Fuentes}

Este artículo responde a una investigación cualitativa de carácter histórico, basada en exclusiva en fuentes de archivo. La escasa bibliografía existente sobre la figura de Casimiro Meseguer ha obligado a reconstruir sus actuaciones partiendo prácticamente desde cero, mientras que las dificultades para encontrar datos personales y relatos de vida que pudieran aproximarnos a su trayectoria vital han limitado el estudio al ámbito profesional. Dada la dilatada carrera de Meseguer como Director de Caminos de la ciudad de Valencia, la mayoría de la información se ha obtenido en el Archivo Histórico Municipal de esta ciudad. Aunque están desperdigados por todos los fondos del archivo, el grueso de los datos se ha extraído de los correspondientes a la sección de Fomento y, en particular, a las clases y subclases de la subsección de Policía Rural (Río Turia y acequias, Rondas y caminos, Paseos y Arbolado, etc.). Algunos de los planos y dibujos que acompañaban a estos expedientes se encuentran actualmente en la valiosa sección que lleva el nombre de D. Emilio Rieta, arquitecto municipal de Valencia hasta 2004 (Faus, 2017 y 2018b).

Los datos de filiación de Casimiro Meseguer se han localizado en el Archivo Histórico Municipal de Sueca (Valencia), su localidad de nacimiento, mientras que su formación académica y su pertenencia al cuerpo de Ayudantes de Obras Públicas se han podido documentar en la Biblioteca Nacional de España, el Archivo General del Ministerio de Fomento y la Biblioteca-Archivo de la Escuela Técnica Superior de Ingeniería Civil de Madrid, heredera esta última de la Escuela Especial de Ayudantes de Obras Públicas fundada en 1857. Datos de menor importancia se han obtenido en el Archivo General y Fotográfico de la Diputación Provincial de Valencia y en el Archivo Digital del Congreso de los Diputados de Madrid. La consulta de la Gaceta de Madrid y los escalafones publicados del cuerpo de Ayudantes de Obras Públicas nos ha permitido introducir el marco legislativo que condicionó la carrera profesional de Meseguer. Las circunstancias de su óbito y entierro, por último, se han conocido gracias a consultas telemáticas en las principales hemerotecas del país.

\section{2. Ámbito de estudio}

La ciudad de Valencia en la que vivió y trabajó Casimiro Meseguer se localiza al este de la península Ibérica y es la capital de la actual Comunidad Valenciana, territorio histórico del antiguo Reino de 
Valencia. Situada a orillas del Mediterráneo y atravesada por el río Turia, domina una amplia llanura litoral, conocida como Huerta de Valencia. Al igual que en la mayoría de las ciudades españolas, su expansión física sobre el entorno no se aceleró hasta que se inició el derribo de las murallas medievales que la constreñían en 1865. La persistencia de la morfología de la ciudad puede comprobarse en las vistas que le dedicó Anton van den Wyjngaerde (1563) y en los planos de Antonio Mancelli (1608), Tomás Vicente Tosca (1704) y Francisco Ferrer (1831). Encerrada en su vieja muralla, hasta la segunda mitad del siglo XIX las puertas de la ciudad se abrían a un espacio en el que continuaban dominando los campos de cultivo, los baldíos y los aguazales. Desde ese momento, mientras en el casco histórico la densificación humana llevaba a continuas reformas del callejero y al aprovechamiento de los solares liberados por los procesos de desamortización y desvinculación, la urbanización extramuros se materializaba gracias a la alineación de los caminos preexistentes y la ocupación de los terrenos contiguos vacíos.

La red de caminos que rodeaba a la ciudad de Valencia en esa época respondía a la configuración propia de un espacio de huerta. Hasta la apertura de las carreteras y líneas de ferrocarril finiseculares, formaba una malla radial que estaba condicionada por el trazado de las acequias de riego y la dispersión de los poblados próximos. En esta malla, sólo los caminos reales habían originado arrabales de una cierta entidad. Hacia el oeste y el sur se dirigían los que unían la ciudad con Madrid a través de los puertos de las Cabrillas y Almansa; hacia el norte, salvado el río Turia, se dirigía el de Morvedre, que llegaba hasta Sagunto partiendo del puente de Serranos y se bifurcaba luego hacia Aragón y Cataluña. Junto a estos caminos reales destacaban los dos locales que conducían al puerto y los poblados marítimos, situados al este de la ciudad, y el que iba hacia el cementerio extramuros. El camino Hondo (o Viejo) del Grao partía desde la puerta del Mar y el llano del Remedio, mientras que el camino Nuevo del Grao, inaugurado en 1802, lo hacía desde el final del paseo de la Alameda. El del Cementerio, por su parte, fue abierto al sur de la ciudad tras las Reales Pragmáticas de 1787 y 1804 que obligaron a que los camposantos se trasladasen fuera de los recintos habitados.

Figura 1. Plan de Valence, 1812

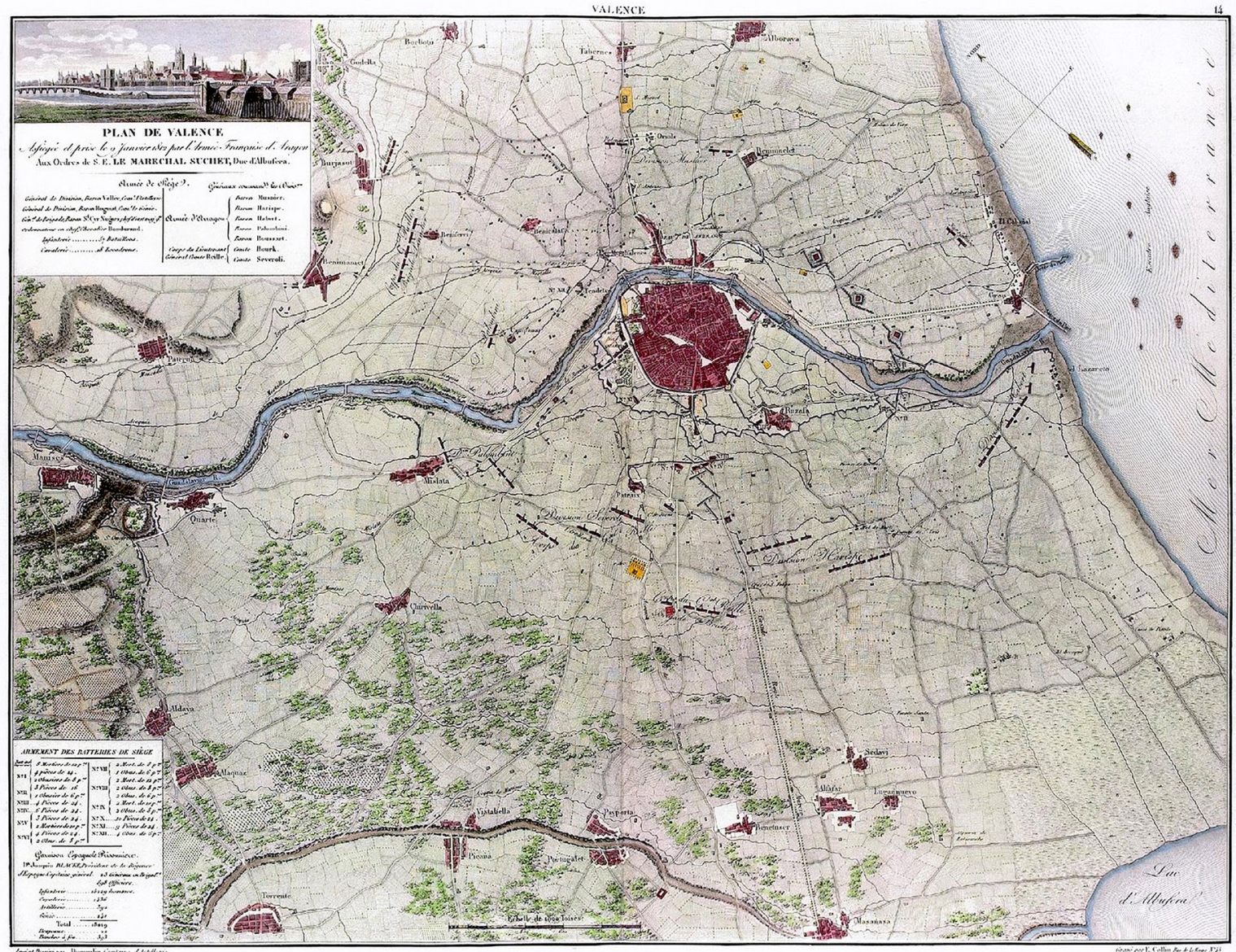

Fuente: Mémoires du maréchal Suchet (...). Paris: Adolphe Bossange, 1828. Cartoteca de la Universitat de València 
En un segundo nivel de importancia se situaban los caminos que enlazaban el centro urbano con los núcleos próximos que pronto absorbería y, algo más allá, con los pueblos que formaban la primera corona metropolitana. Esta red básica, escasamente organizada, contaba con multitud de ramificaciones y caminos transversales. Además de los numerosos camins de la mar que se dirigían hacia la costa desde todos los poblados de la huerta, entre los campos de cultivo y los humedales discurrían decenas de sendas y caminos menores que conducían a las alquerías aisladas y a los molinos a los que daban servicio. A todos ellos se sumaban, finalmente, los caminos propios de los poblados anexionados por Valencia en el periodo que nos ocupa. Una simple ojeada a los planos que forman el Atlas del asedio de las tropas del mariscal Suchet durante la guerra de la Independencia (1828) es suficiente para constatar la maraña de caminos y sendas que envolvía a la ciudad amurallada y estaba al cuidado de la Dirección de Caminos que dirigía Casimiro Meseguer (Figura 1).

\section{Resultados: carrera profesional de Casimiro Meseguer Bonet}

\subsection{Titulación como Ayudante de Obras Públicas}

Nada se sabe de Casimiro Meseguer hasta 1864, cuando ingresó en la Escuela Especial de Ayudantes de Obras Públicas de Madrid. Esta escuela fue creada mediante un Real Decreto de 4/II/1857, firmado por el ministro Claudio Moyano, en el que se justificaba esta decisión por la necesidad de aumentar el número de ayudantes al servicio del Estado (desde los poco más de 200 en activo a 500), ante la creciente demanda de los gobiernos provinciales, los ayuntamientos y las empresas particulares concesionarias del ferrocarril y de las grandes obras públicas. Moyano atribuía la falta de profesionales cualificados a las dificultades para extender en nuestro país "cierta clase de conocimientos" (técnicos), a la carestía de los estudios y, sobre todo, a los mayores salarios ofrecidos por las empresas privadas. En su opinión, la creación de una escuela donde se impartiesen enseñanzas "no literarias" solventaría las urgencias a corto plazo y ofrecería a los jóvenes "una carrera honrosa y de seguro porvenir". ${ }^{3}$

La escuela se instaló en el edificio de la calle del Turco que albergaba la Escuela de Ingenieros de Caminos, Canales y Puertos desde 1847 y estuvo abierta, en su primera etapa, hasta 1868. Su primer director fue el ingeniero Calixto de Santa Cruz, a la sazón también director de la Escuela de Ingenieros, que sería sustituido en 1865 por Lucio del Valle. Junto a Calixto de Santa Cruz inauguraron el centro los ingenieros jefes de $2^{a}$ clase Juan López del Rivero, en calidad de subdirector, y Práxedes Mateo Sagasta, en la de profesor titular. La obligatoriedad de obtener el título correspondiente para poder ingresar en el cuerpo de Ayudantes de Obras Públicas garantizó el éxito de la escuela desde su inauguración. El número de aspirantes al ingreso dobló al de plazas ofertadas desde los primeros cursos y el de los alumnos matriculados de primer año siempre rondó el centenar (Dirección General de Obras Públicas, 1859 y 1861; Ramos, 2007).

El plan de estudios de la escuela contemplaba dos cursos, subdivididos a su vez en dos clases y prácticas de verano (Tabla 1). El primer año se consolidaban las materias de las que ya se había examinado el alumno en la prueba de ingreso (aritmética, álgebra y geometría) y se introducían las primeras nociones de trigonometría, dibujo y mecánica; en el segundo se atendían la estereotomía de materiales y los fundamentos de la construcción, todo lo relativo a los caminos, los ferrocarriles, los canales de riego y los puertos, y los formularios burocráticos (legislación, contabilidad y documentación). Las prácticas, por su parte, estaban dedicadas al perfeccionamiento del dibujo lineal y topográfico con la pluma y la aguada, la resolución gráfica de problemas de geometría, topografía y estereotomía, la cubicación de desmontes y terraplenes, la construcción de pontones, alcantarillas, etc., el manejo de instrumentos topográficos, el levantamiento de croquis y planos, la medición de distancias y el trazado de carreteras.

De todas las asignaturas que componían el plan de estudios la más interesante para nosotros es la de Caminos Ordinarios que impartía el ingeniero $1^{\circ}$ Eduardo Echegaray en la segunda clase del segundo año. Los libros de texto de los que se extractaban los apuntes dictados en el aula eran el Manual de caminos, que comprende su trazado, construcción y conservación del ingeniero jefe de $1^{\mathrm{a}}$ clase Pedro Celestino Espinosa (1855), el Tratado de la formación de los proyectos de carreteras del ingeniero jefe de $2^{\mathrm{a}}$ clase Mauricio Garrán (1862) y dos manuales de la extensa Encyclopédie de Edme Roret publicada en París: el Nouveau Manuel Complet du Terrassier et de l'Entrepreneur de Terrassements de Ch. Etienne y A. Masson

3 Gaceta de Madrid, n 1496, de 7/II/1857. 
(1850) y el Manuel Complet des Ponts et Chaussées de J. de Gayffier (1857). El temario de la asignatura estaba formado por nueve capítulos: trazado, explanación, firme, obras de fábrica, obras accesorias, organización general de las obras de una carretera, conservación de las carreteras, reparación de las carreteras y formularios (Escuela de Ayudantes de Obras Públicas, 1868).

Tabla 1. Plan de Estudios de la Escuela Especial de Ayudantes de Obras Públicas de Madrid

\begin{tabular}{|c|l|l|}
\hline \multicolumn{1}{|c|}{ Curso } & \multicolumn{1}{|c|}{ Clase } & \multicolumn{1}{c|}{ Asignaturas } \\
\hline \multirow{5}{*}{ Primer Año } & Primera & $\begin{array}{l}\text {-Complemento del álgebra } \\
\text {-Trigonometría rectilínea } \\
\text {-Topografía }\end{array}$ \\
\cline { 2 - 4 } & Segunda & $\begin{array}{l}\text {-Geometría descriptiva } \\
\text {-Mecánica }\end{array}$ \\
\cline { 2 - 4 } & Verano & -Dibujo lineal y topográfico, trabajos gráficos y prácticas \\
\hline \multirow{5}{*}{ Segundo Año } & Primera & $\begin{array}{l}\text {-Estereotomía } \\
\text {-Materiales y construcción en general }\end{array}$ \\
\cline { 2 - 4 } & Segunda & $\begin{array}{l}\text {-Caminos ordinarios } \\
\text {-Nociones generales sobre caminos de hierro, canales de riego, puertos y señales } \\
\text { marítimas } \\
\text {-Nociones sobre legislación, contabilidad y documentación de las obras públicas }\end{array}$ \\
\cline { 2 - 3 } & Verano & \begin{tabular}{l}
-Dibujo lineal y topográfico, trabajos gráficos y prácticas \\
\hline
\end{tabular}
\end{tabular}

Fuente: Escuela de Ayudantes de Obras Públicas, 1868

Casimiro Meseguer completó estos estudios en los cursos 1864-1865 y 1865-1866, graduándose en septiembre de 1866 con el número uno de su promoción. El año obligatorio de prácticas que seguía a la graduación lo cumplió en el distrito de Obras Públicas de Valencia, según consta en una Real Orden de 19/X/1866. Se presentó en el destino a principios de noviembre, quedando a las órdenes del Ingeniero $1^{\circ}$ Francisco Lizárraga. Un mes más tarde, su tutela pasó al Ingeniero $1^{\circ}$ Alejandro Cerdà, con quien acabaría licenciándose el 17 de noviembre de 1867. Nacido en Madrid en 1838, Cerdà era Ingeniero $1^{\circ}$ desde mayo de 1862 y prestaba servicio, en ese momento, en la Jefatura de Obras Públicas de Valencia. Estuvo destinado en ella hasta 1874, con un breve intervalo en la División de Ferrocarriles de Valencia en 1871. En septiembre de 1874 fue nombrado Ingeniero Director del puerto de Valencia, cargo que ocuparía hasta 1882. ${ }^{4}$

Las prácticas tuteladas por Cerdà a las que tuvo que enfrentarse Casimiro Meseguer consistieron en el replanteo del tramo 10 de la carretera de $2^{\circ}$ orden que iba desde Játiva hasta Alicante y la realización de distintos trabajos en el puerto de Valencia (nivelación de terrenos, delineación de planos, sondeos, toma de datos para cubicaciones y valoraciones, y ejercicios de contabilidad). La cartilla de notas que se conserva en su expediente administrativo nos indica que obtuvo unas notas finales excelentes: "Muy Buena" en los apartados de Aplicación, Conducta y Aprovechamiento de las Prácticas y "Bastante" en el de Subordinación. ${ }^{5}$ Aprobadas estas prácticas, Meseguer fue destinado al mismo distrito de Obras Públicas de Valencia, donde permanecería hasta 1873, salvo un breve paso por el distrito de Cuenca en el curso 18681869. Finalmente, en abril de 1873 fue adscrito a la plantilla de la Diputación Provincial de Tarragona.

Sin embargo, aquejado de una enfermedad respiratoria que le hizo tomar los baños en el balneario de la Vilavella (Castellón) en julio de ese mismo año, ya no volvería a la ciudad catalana. En septiembre quedaría en expectativa de destino y un año más tarde empezaría su carrera como Director de Caminos de la ciudad de Valencia. A pesar de que nunca más ejercería como Ayudante de Obras Públicas, la inercia burocrática hizo que Casimiro Meseguer fuera acumulando destinos (Huelva y, nuevamente, Tarragona) y ascensos en este cuerpo hasta su jubilación como Ayudante $1^{\circ}$ y Jefe de Negociado de $1^{a}$ Clase en noviembre de 1911 (Tabla 2).

4 Véase la nota biográfica que acompañaba a la necrológica publicada en la Revista de Obras Públicas del 16/VII/1896. Año XLIII, Serie 6ª Tomo II, $\mathrm{n}^{\mathrm{o}} 3$.

5 Toda la información que sigue de la carrera de Meseguer como Ayudante de Obras Públicas en: Archivo General del Ministerio de Fomento, Madrid (AGMF): Inventario 7, Legajo 6441. 
Tabla 2. Carrera profesional de Casimiro Meseguer como Ayudante de Obras Públicas

\begin{tabular}{|c|c|c|c|}
\hline Real Orden & Escalafón & Destino & Notas \\
\hline 19/X/1866 & Ayudante en práctica & Valencia & $\begin{array}{l}\text { Prácticas tuteladas por el Ingeniero } 1^{\circ} \text { Alejandro Cerdà } \\
(26 / \mathrm{XII} / 1866-17 / \mathrm{XI} / 1867)\end{array}$ \\
\hline 28/II/1868 & Ayudante $4^{\circ}$ de Obras Públicas & Valencia & Cesa el 20/VI/1868 \\
\hline 31/V/1868 & Ayudante $4^{\circ}$ de Obras Públicas & Cuenca & Cesa el 8/IV/1869 \\
\hline 4/III/1869 & Ayudante $4^{\circ}$ de Obras Públicas & Valencia & Cesa el 1/IX/1871 \\
\hline 19/VIII/1871 & $\begin{array}{l}\text { Ayudante } 4^{\circ} \text { de Obras Públicas en } \\
\text { excedencia }\end{array}$ & & $\begin{array}{l}\text { Reforma de la plantilla del personal facultativo subalterno } \\
\text { de Obras Públicas. Real Decreto de 12/VIII/1871 }\end{array}$ \\
\hline 20/II/1872 & Ayudante $4^{\circ}$ de Obras Públicas & Valencia & Cesa el 1/IV/1873 \\
\hline 22/III/1873 & Expectativa de destino & & \\
\hline 8/IV/1873 & Ayudante $4^{\circ}$ de Obras Públicas & Tarragona & $\begin{array}{l}\text { Licencia de dos meses por enfermedad desde el } \\
\text { 22/VII/1873. } \\
\text { Cesa el 19/IX/1873 }\end{array}$ \\
\hline 4/IX/1873 & Expectativa de destino & & \\
\hline 30/VII/1875 & $\begin{array}{l}\text { Licencia ilimitada como Ayudante } \\
\text { Supernumerario del cuerpo de } \\
\text { Ayudantes de Obras Públicas. }\end{array}$ & & $\begin{array}{l}\text { Director interino de Caminos Vecinales de Valencia el } \\
\text { 24/XI/1874. Titular desde el 1/VII/1875. Solicitud de } \\
\text { licencia ilimitada el 5/VII/1875 }\end{array}$ \\
\hline 16/XII/1880 & & Huelva & $\begin{array}{l}\text { Dado de alta por Real Orden de 20/XI/1880. No toma } \\
\text { posesión por ejercer "al servicio de corporación" }\end{array}$ \\
\hline 12/V/1881 & Ayudante $3^{\circ}$ de Obras Públicas & & \\
\hline 9/VII/1887 & Ayudante $2^{\circ}$ de Obras Públicas & Tarragona & No toma posesión por ejercer "al servicio de corporación" \\
\hline 26/VII/1892 & $\begin{array}{l}\text { Ayudante } 2^{\circ} \text { de Obras Públicas, } \\
\text { Oficial } 3^{\circ} \text { de Administración }\end{array}$ & & $\begin{array}{l}\text { Reorganización de la plantilla del cuerpo de Ayudantes } \\
\text { de Obras Públicas. Real Decreto de 19/VII/1892 }\end{array}$ \\
\hline 7/III/1895 & $\begin{array}{l}\text { Ayudante } 2^{\circ} \text { de Obras Públicas, } \\
\text { Oficial } 2^{\circ} \text { de Administración }\end{array}$ & & \\
\hline 29/XII/1900 & $\begin{array}{l}\text { Ayudante } 2^{\circ} \text { de Obras Públicas, } \\
\text { Oficial } 1^{\circ} \text { de Administración }\end{array}$ & & Antigüedad desde 9/XII/1900 \\
\hline 20/X/1902 & $\begin{array}{l}\text { Auxiliar } 2^{\circ} \text { de Obras Públicas, } \\
\text { Oficial } 1^{\circ} \text { de Administración }\end{array}$ & & $\begin{array}{l}\text { Reforma de las plantillas de Ayudantes y Sobrestantes de } \\
\text { Obras Públicas. Real Decreto de 3/X/1902 }\end{array}$ \\
\hline 26/IX/1905 & $\begin{array}{l}\text { Ayudante } 1^{\circ} \text { de Obras Públicas, Jefe } \\
\text { de Negociado de } 3^{\text {a }} \text { clase }\end{array}$ & & Antigüedad desde 1/IX/1905 \\
\hline 10/I/1908 & $\begin{array}{l}\text { Ayudante } 1^{\circ} \text { de Obras Públicas, Jefe } \\
\text { de Negociado de } 2^{\text {a }} \text { clase }\end{array}$ & & Antigüedad desde 1/I/1908 \\
\hline 8/XI/1911 & $\begin{array}{l}\text { Jubilación como Ayudante } 1^{\circ} \text { de } \\
\text { Obras Públicas, Jefe de Negociado } \\
\text { de } 1^{\text {a }} \text { clase }\end{array}$ & & \\
\hline
\end{tabular}

Fuente: Archivo General del Ministerio de Fomento (Madrid): Inventario 7, Legajo 6441; Ministerio de Fomento, 1882 y 1893

\subsection{Director de Caminos de la ciudad de Valencia}

\subsubsection{Nombramiento}

Entre los asuntos que competían a los negociados municipales de Policía Urbana y Rural ya mencionados, se encontraban la vigilancia del orden público y la actividad edilicia, la gestión de las contratas de empedrado, alumbrado y limpieza, la conservación de fuentes, puentes y caminos, la vigilancia de las servidumbres de paso viario, el pronto socorro en caso de incendio, inundación o derrumbe y la inspección de las acequias y los canales de riego. En la ciudad de Valencia, con la entrada en vigor de la Ley de Ayuntamientos de 1840, la dirección nominal de estos asuntos recayó en su alcalde-corregidor, quien la delegó en varias de las comisiones permanentes del consistorio. El ramo de Caminos acabaría integrándose, hasta 1874 y con el rango de Subcomisión de Puentes y Caminos, en la Comisión de Policía Urbana y Rural.

En el último cuarto del siglo XIX, este ramo cambiaría varias veces de nombre y situación administrativa: Comisión de Paseos y Caminos (1874-1877); Comisión de Caminos, Puentes y Pretiles (1877-1881); Comisión de Caminos, Paseos y Policía Rural (1881-1900) y Comisión de Caminos y Policía Rural (desde 
diciembre de 1900). En febrero de 1897 se convirtió en una subsección de la Sección de Fomento y, desde julio de 1899, se desligaron de ella las comisiones especiales del Camino de Tránsitos y, hasta enero de 1904, del Camino Paseo Valencia al Mar. Con independencia de su nombre, siempre existió en estos negociados un Director de Caminos encargado de la red viaria extramuros, que ejerció sus funciones en paralelo al Director de Paseos, Arboledas y Jardines. La creación del empleo fue consecuencia de la prerrogativa que, en este sentido, les fue concedida a los alcaldes en la Ley de Caminos Vecinales de 28/IV/1849. ${ }^{6}$

La Dirección de Caminos, literalmente Dirección Facultativa de los Caminos Municipales de Valencia, fue instituida en el ayuntamiento de esta ciudad en enero de 1874, cuando el pleno municipal, a instancias de la Subcomisión de Puentes y Caminos, solicitó al alcalde el nombramiento de "un auxiliar inteligente" que se hiciese cargo de los trabajos que precisaban los caminos del término. Entre las razones aducidas se incluía el deplorable estado en el que se encontraban estos caminos a causa del aumento del tráfico viario y la necesidad de que se controlasen los elevados gastos que comportaba su mantenimiento, sobre todo en época de lluvias. Este problema afectaba en particular al camino Nuevo del Grao, motivo por el que se pedía que la persona elegida estuviera obligada a elaborar un proyecto que lo reformase por completo. Al proceso de selección se presentaron dos aspirantes, Rafael Sociats y Casimiro Meseguer, siendo elegido el primero de ellos por votación secreta entre los miembros de la Subcomisión. ${ }^{7}$

Rafael Sociats (Ciudad Rodrigo, 1822) ya había presidido la propia Subcomisión a finales de 1868 en calidad de alcalde $6^{\circ}$ del ayuntamiento revolucionario. Su toma de posesión se produjo el 12 de febrero de 1874, una vez que presentó, de manera simultánea, el título de Director de Caminos Vecinales que poseía desde 1851 y el proyecto de reforma del camino Nuevo del Grao al que se había comprometido. ${ }^{8}$ Sin embargo, las exigencias del cargo hicieron que apenas estuviera en él cuatro meses. En junio de 1874 dimitió, primero como encargado de las obras que se estaban realizando en el paseo de la Alameda y, luego, como director interino de Caminos. En esos cuatro meses había dirigido trabajos específicos en los puentes de Serranos, de la Trinidad, del Mar y de San José, en diversas calles extramuros, en los llanos de la Zaidía y la Trinidad, y en los caminos de la Pechina y Hondo del Grao. ${ }^{9}$

La elección recayó entonces en Casimiro Meseguer, nombrado director interino en noviembre de 1874 y titular del empleo en junio de $1875 .{ }^{10}$ En el entreacto, el Reglamento de Personal Facultativo del ayuntamiento de Valencia, aprobado en abril de 1875, estableció que los títulos que habilitaban para ejercer este empleo eran los de Director de Caminos Vecinales, Ingeniero o Ayudante de Obras Públicas. ${ }^{11}$ Como hemos visto, Meseguer había obtenido el último de ellos en la Escuela Especial de Ayudantes de Obras Públicas de Madrid en 1866. Aunque había ingresado en el cuerpo de Ayudantes de Obras Públicas en febrero de 1868, en el momento de su nombramiento se encontraba en expectativa de destino (director interino) y con licencia ilimitada como ayudante supernumerario (director titular). Un Real Decreto de 25/III/1881 consolidó su situación al dictaminar que el personal subalterno de Obras Públicas podía pasar al servicio de ayuntamientos y diputaciones sin perder sus derechos administrativos si tenía un mínimo de dos años de antigüedad en el cuerpo (Navascués y Pinillos, 1892).

Debió de ser durante el tiempo que estuvo destinado en Valencia como Ayudante en Práctica y $4^{\circ}$ de Obras Públicas cuando Casimiro Meseguer consiguió los contactos que le permitieron presentarse al concurso de Director de Caminos en enero de 1874. En su interés por el cargo debieron de pesar tanto la posibilidad de estabilizar la situación familiar tras el nacimiento de su segunda hija como la mejora salarial que implicaba. ${ }^{12}$ Liberado de sus obligaciones con el ministerio de Fomento a finales de 1873, se había establecido en Valencia, donde se casó con Ramona Bernardo Perpiñán y, tras enviudar, con Manuela Benedito Gregori. Tuvo nueve

6 Ley sobre construcción, conservación y mejora de los Caminos Vecinales, de 28/IV/1849, Art. 10. Esta posibilidad ya estaba recogida en el Reglamento del Real Decreto de 7/IV/1848, Arts. 78-79.

7 Archivo Histórico Municipal de Valencia (AHMV): Libro de Actas y Documentos, 15/1/1874; y Libro de Actas de la Comisión de Paseos y Caminos, 23/I/1874. Rafael Sociats obtuvo 7 votos frente a los 6 de Casimiro Meseguer.

8 AHMV: Personal. Policía Rural, 12 y 14/II/1874. El título de Director de Caminos Vecinales de Rafael Sociats le fue expedido en 1851, con la firma del Director de Instrucción Pública, Antonio Gil de Zárate, tras haber demostrado su competencia ante el Gobernador de Teruel en octubre de 1850 .

9 AHMV: Libro de Actas de la Comisión de Policía Urbana y Rural, 15/VI/1874; y Libro de Actas y Documentos, 18/VI/1874.

10 AHMV: Libro de Actas de la Comisión de Policía Urbana y Rural, 24/XI/1874; Libro de Actas de la Comisión de Paseos y Caminos, 4/ VI/1875; y Libro de Actas y Documentos, 14/VI/1875.

11 AHMV: Libro de Actas y Documentos, 3/V/1875, Art. $3^{\circ}$

$12 \mathrm{Al}$ estar en la situación de expectativa de destino y con licencia ilimitada como ayudante supernumerario de Obras Públicas, el sueldo de Casimiro Meseguer se había reducido a la mitad. En 1874 era de apenas 1.500 pesetas, frente a las 2.500 pesetas que percibía como Director de Caminos. 
hijos: tres con su primera mujer (Carmen, 1869; Dolores, 1873; y Casimiro, 1874) y seis con la segunda (Manuela, 1879; Aurelio, 1884; Enrique, 1886; Pura, 1887; Vicente, 1891; y José, 1893). ${ }^{13}$

El cargo de Director de Caminos al que accedió Casimiro Meseguer dependió administrativamente de la Sección Facultativa de Policía Urbana hasta 1889, cuando la puesta en marcha del ensanche de la ciudad aprobado en 1887 obligó a una profunda reorganización de la plantilla municipal de obras públicas (Faus, 2018a). Tras esta reorganización, quedó bajo la jurisdicción exclusiva de la Comisión de Caminos, Paseos y Policía Rural y sus funciones quedaron muy limitadas. La expansión física del casco urbano limitó la importancia del espacio no edificado y alejó al Director de Caminos de la gestión interior. En octubre de 1900, una comisión mixta especificó que debía encargarse únicamente de los servicios que precisaran las vías públicas que no quedaran bajo la supervisión de las comisiones de Policía Urbana y Ensanche. Esto es, de las alejadas del casco histórico, los ensanches y los poblados anexionados (Figura 2). ${ }^{14}$

Figura 2. Plano del camino Nuevo de Nazaret. Casimiro Meseguer, 1903

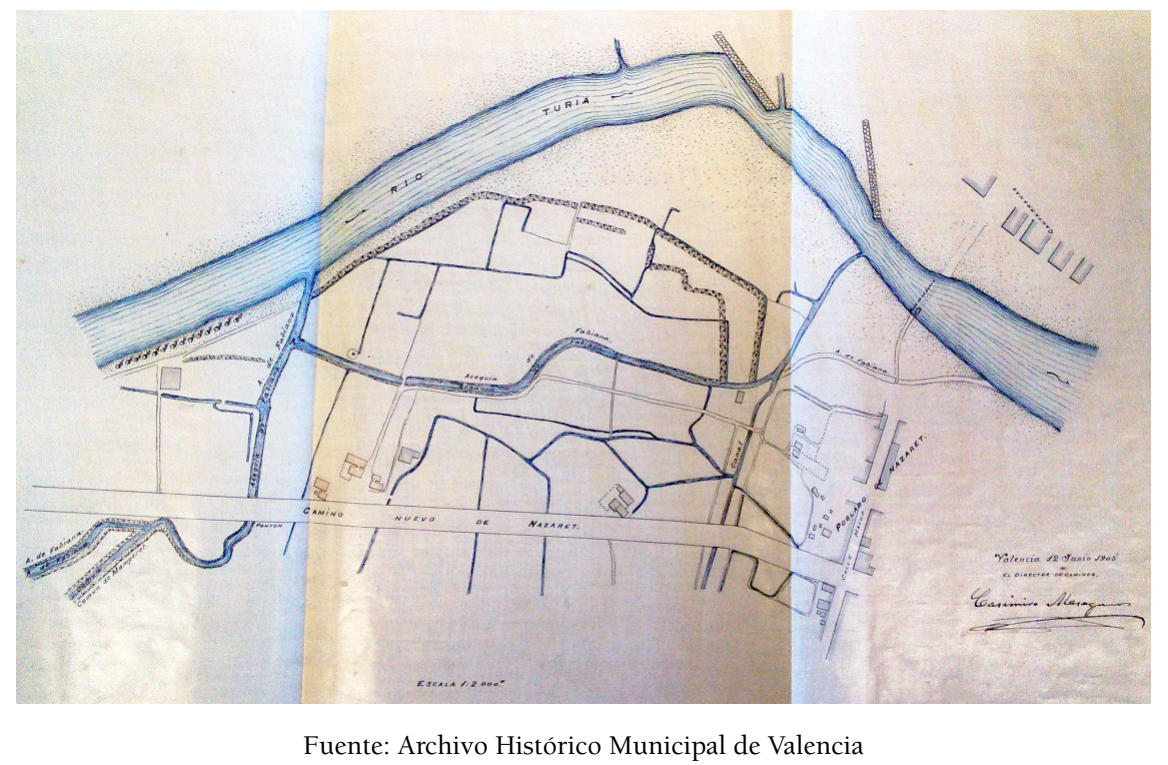

Casimiro Meseguer ocuparía el cargo de Director de Caminos de la ciudad de Valencia ininterrumpidamente hasta su muerte el 1 de enero de 1915, momento en el que sería reemplazado por José Burguera. En todo ese tiempo, su situación administrativa sólo pudo variar a finales de 1897, cuando fue propuesto, sin éxito, para ocupar el cargo de Director de Vías Municipales que ya existía en Madrid y Barcelona. ${ }^{15}$ Sus condiciones de trabajo también fueron siempre las mismas, salvando el hecho de que desde noviembre de 1891 pudo disponer de un despacho propio, una vez que se construyeron unos tabiques que lo separaron del que compartía con la Comisión de Beneficencia y Sanidad. Estaba situado en el Archivo Municipal y ocupaba el espacio que había correspondido hasta entonces a la sección del Padrón. ${ }^{16}$

El nombramiento de Casimiro Meseguer dotó a la Dirección de Caminos de una gran estabilidad. Bajo sus órdenes, la plantilla no dejaría de ampliarse. De los cuatro empleos existentes en 1875 (director, sobrestante, capataz y peón caminero) se pasó a trece en 1914 (Tabla 3). De estos empleos el único creado a la vez que el de director fue el de sobrestante. Lo ocuparon cinco personas entre 1874 y 1915: Francisco Climent (1874-1875); Matías Albert (1875-1878); José María Albert (1878-1902); Antonio Albors (18901903); y Salvador Montañés (desde 1902). Los restantes se incorporaron a la Dirección de Caminos a medida que crecían sus obligaciones: el de auxiliar facultativo, en 1886; el de delineante, en 1903; el de delineante auxiliar, en 1904; el de escribiente mecanógrafo, en 1911; el de cabo capataz de las brigadas de peones camineros, en 1913, etc. ${ }^{17}$

13 AHMV: Libros Padrones, 1875-1915.

14 AHMV: Fomento. Policía Urbana. Disposiciones Generales, 22/X/1900.

15 AHMV: Fomento. Policía Urbana. Disposiciones Generales, 3 y 6/XII/1897.

16 AHMV: Libro de Actas de la Comisión de Personal y Gobierno Interior, 13/XI/1891.

17 AHMV: Fomento. Personal. Licencias, Asistencia y Hojas de Servicio, Caja 5. 
Tabla 3. Plantilla facultativa de la Comisión de Caminos y Policía Rural en 1914

\begin{tabular}{|l|c|c|}
\hline \multicolumn{1}{|c|}{ Empleo } & $\begin{array}{c}\text { Número de } \\
\text { empleados }\end{array}$ & Sueldo anual (pts.) \\
\hline Director de Caminos & 1 & 4.500 \\
\hline Auxiliar Facultativo de Caminos & 1 & 2.750 \\
\hline Sobrestante de Caminos y Cementerios & 1 & 2.500 \\
\hline Delineante & 1 & 1.999 \\
\hline Delineante Auxiliar para los trabajos topográficos & 1 & 1.999 \\
\hline Auxiliar del Sobrestante de Caminos y Cementerios & 2 & 1.500 \\
\hline Escribiente Mecanógrafo & 1 & 1.500 \\
\hline Capataz de las brigadas de peones camineros & 1 & 1.500 \\
\hline Cabo de las brigadas de peones camineros & 1 & 1.250 \\
\hline Peón caminero encargado del almacén de materiales & 1 & 999 \\
\hline Peón caminero portamiras & 1 & 999 \\
\hline Peón caminero & 34 & 912,50 \\
\hline Peón caminero encargado de las compuertas del Valladar & 1 & 150 (dieta) \\
\hline
\end{tabular}

Fuente: Archivo Histórico Municipal de Valencia: Fomento. Policía Rural, Varia

\subsubsection{Trabajos y proyectos}

El empleo de Director de Caminos obligó a Casimiro Meseguer a intervenir en multitud de cuestiones. Desde su nombramiento fue el máximo responsable del diseño, la composición y el mantenimiento de toda la red de caminos vecinales del término municipal de Valencia y su infraestructura anexa (puentes, tageas, pasos adoquinados, cruces ferroviarios, alcantarillas, brazales de riego, etc.). De todas ellas, las obligaciones que suponían una mayor dedicación en el día a día eran el cuidado del firme de los caminos, la inspección de obras que necesitaban de un informe favorable para su ejecución (el vallado de terrenos, la apertura de puntos de acceso a las propiedades colindantes, etc.) y la vigilancia de las actuaciones que se consideraban lesivas para el municipio (la apropiación de los márgenes de los caminos, el deterioro de las obras de fábrica, los cultivos ilegales, etc.). La relación de los trabajos llevados a cabo bajo la dirección de Meseguer sería interminable (Tabla 4).

Tabla 4. Trabajos destacados de Casimiro Meseguer como Director de Caminos de la ciudad de Valencia

\begin{tabular}{|l|l|}
\hline AÑO & \multicolumn{1}{|c|}{ TRABAJO } \\
\hline 1875 & Redacción del Reglamento de Conservación y Policía de Caminos Vecinales y Rurales \\
\hline 1875 & Proyecto de reforma del paseo de la Alameda. Renovado en 1885 \\
\hline 1876 & Ensanche del camino del Cementerio General \\
\hline 1877 & Diseño del óvalo del camino Nuevo del Grao en su unión con la Alameda \\
\hline 1879 & Proyecto de defensas ante inundaciones en el poblado de Campanar \\
\hline 1881 & Plano general de todos los caminos vecinales, rurales, sendas y veredas del término \\
\hline 1882 & Plan de carreteras del término, según circular del Gobernador Civil. También en 1888, 1893 y 1902 \\
\hline 1882 & Reglamento sobre Policía del río Turia desde la Pechina hasta la presa del Canal \\
\hline 1883 & Estado general de denominaciones y antecedentes de los caminos vecinales del término \\
\hline 1883 & Plano del río Turia desde el puente de San José hasta la presa de Rovella \\
\hline 1884 & Proyecto de instalación de vías metálicas en el camino Nuevo del Grao. Presentado en 1887 \\
\hline 1884 & Composición de numerosos caminos vecinales tras las lluvias torrenciales de octubre de 1884 \\
\hline 1885 & Relación de los pasos adoquinados necesarios para los caminos y calles de los arrabales \\
\hline 1885 & Memoria sobre canteras de la provincia de Valencia \\
\hline 1885 & Estudio para la mejora del sistema de afirmado de las calles de la ciudad \\
\hline
\end{tabular}




\begin{tabular}{|c|c|}
\hline 1887 & Proyecto de alineación del camino de Benimaclet \\
\hline 1887 & Memorias sobre pruebas de afirmado en la calle de Colón y el camino Nuevo del Grao \\
\hline 1888 & Presentación del proyecto definitivo de paseo-camino de Valencia al Mar \\
\hline 1888 & Visita a la Exposición Universal de Barcelona \\
\hline 1890 & Plano del proyecto de ensanche llamado del Este \\
\hline 1890 & Plano de todos los caminos del poblado de Ruzafa \\
\hline 1893 & Informe sobre construcción de puente metálico entre los puentes de Serranos y de la Trinidad \\
\hline 1895 & Informe sobre obras de ampliación del puerto de Valencia \\
\hline 1895 & Proyecto de construcción del camino de Tránsitos de Consumos en sus dos primeras secciones \\
\hline 1895 & Informe sobre construcción de puente de hierro frente al poblado de Nazaret \\
\hline 1896 & Proyecto de construcción del camino de Tránsitos de Consumos en su sección Este \\
\hline 1900 & Deslinde entre Valencia y Burjassot para el Instituto Geográfico Nacional \\
\hline 1900 & Deslinde del Valladar, entre la casa de compuertas y el río Turia \\
\hline 1901 & Proyecto de camino desde Nazaret al poblado de El Saler, junto al canal de la Albufera \\
\hline 1903 & Dictamen con medidas para favorecer el libre curso de las aguas del río Turia \\
\hline 1903 & Aprobación del proyecto de alineaciones del camino de Tránsitos de Consumos del Este, ahora del Norte \\
\hline 1903 & Proyecto de camino desde Valencia a Sueca, por Pinedo, El Saler y El Perelló \\
\hline 1904 & Aprobación del proyecto de rectificación y ensanche del camino de la Fuente de San Luis \\
\hline 1905 & Proyecto de aprovechamiento de la Dehesa de la Albufera \\
\hline 1906 & Reforma del puente del Mar \\
\hline 1908 & Medición de terrenos para la construcción de la Facultad de Medicina en el paseo-camino Valencia al Mar \\
\hline 1909 & Informe sobre utilización de piedra basáltica en los afirmados de los caminos del término \\
\hline 1909 & Anteproyecto de camino desde el puente del Mar hasta El Saler \\
\hline 1910 & Informe sobre el establecimiento de balsas salinas en la desembocadura del río Turia \\
\hline 1911 & Memoria, presupuesto y perfiles para la instalación de vías metálicas en el camino de Tránsitos de Consumos \\
\hline 1911 & Proyecto de camino de Valencia a la Albufera. Declarado de utilidad pública en 1912 \\
\hline 1914 & Afirmado del camino de Campanar. Premiado en el $2^{\circ}$ Concurso Nacional de Subvenciones de Caminos Vecinales \\
\hline 1914 & Proyecto de puente de hierro frente a la $1^{\text {a }}$ Sección del camino de Tránsitos de Consumos \\
\hline 1914 & Alineación del camino de Pinedo \\
\hline 1914 & Deslinde de terrenos junto a la acequia de Fabiana, en la zona de Francos y Marjales. \\
\hline 1914 & Comisión de deslinde y amojonamiento de todos los caminos y parcelas municipales \\
\hline
\end{tabular}

Fuente: Archivo Histórico Municipal de Valencia. Documentación diversa

Aunque las tareas cotidianas podían asumirlas el sobrestante o el auxiliar facultativo de Caminos, no sucedía lo mismo con la redacción de memorias técnicas sobre cualquier tema que afectase mínimamente a la red de caminos o la elaboración de proyectos que diesen solución a los problemas que iba generando el crecimiento de la ciudad. Entre las múltiples memorias elaboradas por Casimiro Meseguer destacan las que dedicó a las canteras de la provincia de Valencia (1885), el afirmado de la calle de Colón (1887), la visita que realizó a la ciudad de Barcelona con motivo de la Exposición Universal (1888), las obras de ampliación hacia el sur del puerto de Valencia (1895) y el libre curso de las aguas del río Turia (1903). Entre los proyectos, sobresalen los cuatro mayúsculos citados al principio de este artículo.

\section{Reforma del paseo de la Alameda $(1875 ; 1877)$}

Situado en el margen izquierdo del río Turia, fuera del casco histórico de la ciudad de Valencia, el paseo de la Alameda ocupa un espacio privilegiado entre los puentes del Real y del Mar. Aunque en 1644 se plantaron en él las dos filas de álamos que le dieron nombre, no fue hasta la segunda mitad del siglo XIX cuando los arquitectos Jorge Gisbert, Joaquín Tomás Belda y Carlos Spain firmaron los primeros proyectos para conseguir su urbanización definitiva. La adecuación del paseo se inició en abril de 1874 
bajo la supervisión de Rafael Sociats, pero los trabajos quedaron inmediatamente paralizados a causa de su dimisión y de la negativa del arquitecto Manuel Blasco a hacerse cargo de las obras. Durante algo más de un año sólo se llevaron a cabo labores de mantenimiento dirigidas por Miguel Escoin, sobrestante de Caminos. Finalmente, tras fracasar la convocatoria de un concurso público de ideas, el encargo recayó en Casimiro Meseguer en octubre de 1875.

Su proyecto sería aprobado un mes más tarde, sin apenas discusión, por la Comisión de Paseos y Caminos. ${ }^{18}$ La principal innovación que incluía era la eliminación de la medianera arbolada existente en el paseo con el fin de convertirlo en una gran avenida entre el jardín del Real y el camino Nuevo del Grao que sirviera como lugar de tránsito para jinetes y carruajes. Como consecuencia de la reforma, se recuperaba el óvalo situado a los pies del puente del Real con la función de rotonda de acceso al paseo, se procuraba la anexión del Plantío municipal de árboles ya existente y se procedía a la alineación del camino de la Soledad que discurría paralelo a la verja de este último. La regularización dotaba a este camino de una anchura de 10,50 m., que sólo se veía reducida a 9,20 m. entre el molino harinero de Pilares y su intersección con el brazal de Algirós de la acequia de Mestalla.

El andén central del paseo alcanzaba una anchura máxima de 30,80 m. en las proximidades del óvalo situado al final del Plantío (27,60 m. en el resto de la vía) y una anchura mínima de 11,50 m. en la confluencia con la bajada del puente del Mar frente a los cuarteles que se estaban construyendo en los terrenos del ex convento de San Juan de Ribera. A ambos lados de este andén principal se contaba con otros dos peatonales de 3,60 m. de anchura. El resultado era un paseo asimétrico, ya que el andén peatonal situado junto a los pretiles del río tenía una anchura sensiblemente inferior a la del conjunto formado por el andén gemelo, el Plantío y el camino de la Soledad. Sin embargo, no era este el mayor problema: quedaban por resolver la conexión lineal con los caminos Nuevo del Grao y de Benimaclet, y el agostamiento del paseo que provocaba la presencia de la acequia de Mestalla a la altura de San Juan de Ribera.

En marzo de 1877 se formó una comisión municipal para estudiar el modo de conectar el paseo de la Alameda con el camino Nuevo del Grao. Casimiro Meseguer presentó su propuesta de obras en el mes de agosto, siendo aprobada finalmente el 17 de octubre tras ser aceptada por el consistorio y superar el periodo de exposición pública. ${ }^{19}$ La solución al problema consistió en el diseño de una explanada amplia en la bajada del puente del Mar que permitiese la circulación fluida de los carruajes (y, más tarde, del tranvía) (Figura 3). ${ }^{20}$ Hay que recordar que, en esas fechas, el puente del Mar era el último antes de la desembocadura del Turia y que, por lo tanto, concentraba todo el tráfico de mercancías que se dirigía hacia el puerto desde la salida del casco antiguo por el llano del Remedio y desde la huerta de Ruzafa por el camino de Monteolivete. Más tarde, el propio Meseguer se haría cargo del anteproyecto de ensanche del puente del Mar de 1890 e, incluso, de las obras de composición de su firme de 1912. ${ }^{21}$

La necesidad de mejorar el camino de Benimaclet fue puesta de manifiesto por Casimiro Meseguer a finales de 1882, aprovechando una permuta de terrenos con la condesa de Ripalda en el llano del Real. La propiedad de estos nuevos terrenos permitió al ayuntamiento el acondicionamiento de una zona en la que también se iniciaban el camino de la Soledad y el paseo de la Alameda. En 1887, los trabajos de embellecimiento convirtieron a la fuente instalada en el óvalo del puente del Real en el eje desde el que irradiaban las tres vías. El camino de Benimaclet fue alineado completamente, dándole una anchura de $10 \mathrm{~m} .{ }^{22}$ Las obras para cubrir $380 \mathrm{~m}$. de la acequia de Mestalla entre el Plantío y el ex convento de San Juan de Ribera, por su parte, se desarrollaron entre 1884 y 1890 , con un coste final de $47.881,09$ pesetas. $^{23}$ Las dos intervenciones fueron incluidas en el proyecto para la conclusión del paseo de la Alameda que Meseguer y Eduardo Boscà, Director de Paseos, Arboledas y Jardines, firmaron en febrero de 1885. ${ }^{24}$

18 AHMV: Libro de Actas de la Comisión de Paseos y Caminos, 14, 17, 22 y 29/XI/1875. Se conserva una copia de los planos que acompañaban a la memoria de Casimiro Meseguer: un plano de planta a escala 1:200 y otro con once perfiles transversales a escala 1:50. AHMV: Emilio Rieta, Alineaciones, Caja 23; y Cajas Blancas, Caja 58.

19 AHMV: Libro de Actas de la Comisión de Caminos, Puentes y Pretiles, 17/VIII/1877; y Libro de Actas y Documentos, 12/IX/1877 y 17/X/1877.

20 AHMV: Emilio Rieta, Cajas Blancas, Caja 62

21 AHMV: Libro de Actas de la Comisión de Caminos, Paseos y Policía Rural, 17/I/1890; y Libro de Actas, $21 / 1 \mathrm{I} / 1912$.

22 AHMV: Fomento, Policía Rural, Paseos y Arbolados, Subclase A.

23 AHMV: Fomento, Policía Rural, Río Turia y Acequias, Subclase F.

24 AHMV: Actas de la Comisión de Caminos, Paseos y Policía Rural, 10/II/1885 
Figura 3. Copia del proyecto de Casimiro Meseguer de reforma del camino Nuevo del Grao en su conexión con el paseo de la Alameda, 1877

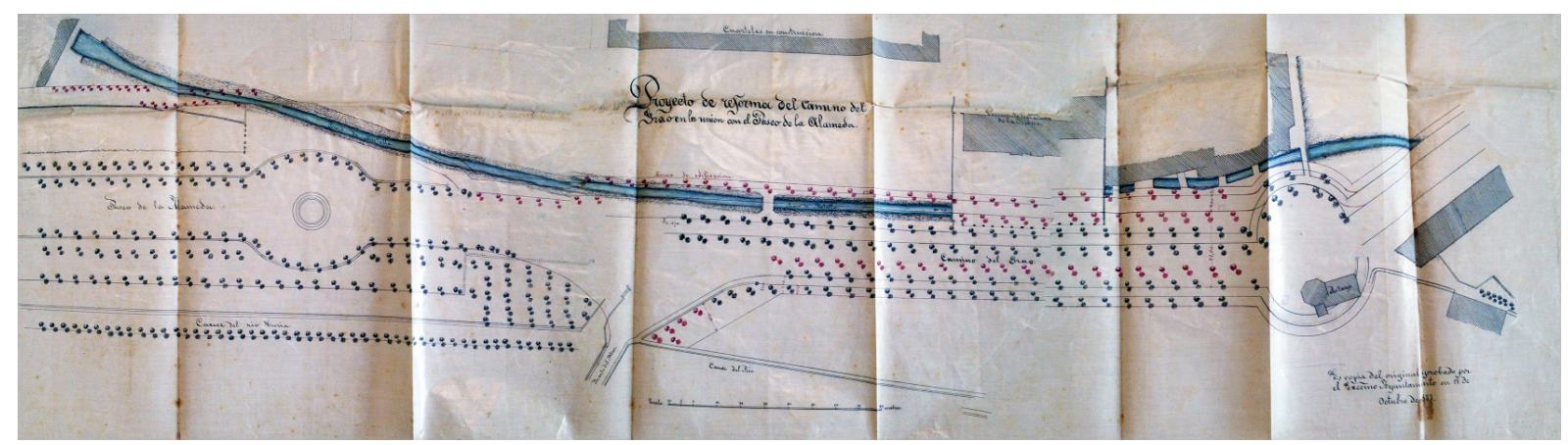

Fuente: Archivo Histórico Municipal de Valencia

\section{Vías metálicas (1884)}

El auge económico de las décadas de 1870 y 1880 revitalizó la circulación de mercancías entre la ciudad de Valencia y su puerto, provocando la proliferación de almacenes y naves industriales en los márgenes de los dos caminos que los unían. El aumento del tráfico puso en evidencia el mal estado habitual de estos caminos, su reducida amplitud y sus constantes cambios de rasante. El desgaste del empedrado de solera obligaba a realizar dos subastas anuales para el suministro de piedra machacada, gasto al que debía sumarse el ocasionado por la compra y el mantenimiento de los cilindros compresores utilizados en las obras de pavimentación. ${ }^{25}$ En los años económicos de 1881-1882 y 1882-1883, los gastos de conservación de los caminos del término ya suponían un tercio del presupuesto total del ramo de Caminos, Paseos y Policía Rural. ${ }^{26}$

La idea de instalar vías metálicas en los caminos de mayor tránsito para evitar el desgaste de su firme fue expuesta por primera vez por Casimiro Meseguer a finales de 1883, al hacerse cargo del arreglo del camino Nuevo del Grao tras las lluvias del otoño. ${ }^{27}$ Un año después, comunicó a la Comisión de Caminos, Paseos y Policía Rural que había iniciado un estudio sobre las ventajas que reportaban estas vías y que estaba esperando la respuesta de varias empresas extranjeras a las que había solicitado muestras y precios. ${ }^{28}$ Aún tendrían que pasar tres años para que el ayuntamiento aceptase su propuesta y aprobase un ensayo con estos carriles en un tramo de $200 \mathrm{~m}$. del camino Nuevo del Grao y otro más para que se llevase a cabo. Los raíles fueron suministrados por la compañía belga Demerbé y fletados desde el puerto de Amberes bajo la supervisión de Meseguer. El éxito de la prueba hizo que el ayuntamiento diera el visto bueno, a finales de 1889, a la extensión de las vías metálicas a todo el camino Nuevo del Grao. ${ }^{29}$

Las obras empezaron en febrero de 1890 en el tramo comprendido entre el óvalo final del paseo de la Alameda y el paso a nivel del ferrocarril a Tarragona. Se decidió recubrir ambos lados de la vía con madera y dejar libre la entrevía, además de reformar las cunetas y el arbolado del camino. La fila interior de árboles que poseía fue eliminada en el mes de abril. ${ }^{30} \mathrm{El}$ pliego de condiciones para la adquisición de $5.500 \mathrm{~m}$. de vía metálica fue aprobado el 1 de marzo, siendo anunciada la subasta simultánea que debía celebrarse en Madrid y Barcelona en la Gaceta de Madrid y el Boletín Oficial de la Provincia de Valencia. Celebrada la subasta el 16 de junio, el pedido fue adjudicado a Francisco Montalt a razón de 40.900 pesetas/kilómetro. Sin embargo, Montalt cedió sus derechos a la compañía francesa de Altos Hornos, Fraguas y Aceros de la Marina y de los Ferrocarriles de Saint Chamond, cuyo representante en Valencia era Rafael Valls. ${ }^{31}$

La compañía Demerbé apeló el resultado de la subasta aduciendo que gozaba del privilegio de invención. Esta reclamación judicial y los continuos retrasos en la entrega del material por parte de la compañía

$25 \mathrm{El}$ primer pliego de condiciones para el abastecimiento de piedra machacada firmado por Casimiro Meseguer, en AHMV: Actas de la Comisión de Paseos y Caminos, 26/VI/1875; el último, en AHMV: Fomento. Policía Rural, Rondas y Caminos, Subclase A, Caja 11. Data del 22/V/1914.

26 AHMV: Actas de la Comisión de Caminos, Paseos y Policía Rural, 29/1/1881 y 2/X/1882.

27 AHMV: Actas de la Comisión de Caminos, Paseos y Policía Rural, 9 y 30/XI/1883.

28 AHMV: Actas de la Comisión de Caminos, Paseos y Policía Rural, 4/XI/1884.

29 AHMV: Actas de la Comisión de Caminos, Paseos y Policía Rural, 8/II, 14/XI y 6/XII/1889.

30 AHMV: Libro de Actas, 21 y 27/II y 14/IV/1890.

31 AHMV: Libro de Actas, 1/III, 16/VI y 6/X/1890. 
concesionaria llevaron al ayuntamiento a solicitar permiso al Gobernador Civil para comprar las vías sin subasta y, a continuación, abrir un nuevo concurso en junio de 1891. Tres meses después, la compañía Demerbé consiguió la adjudicación del suministro de las $5.500 \mathrm{~m}$. de vía metálica acordadas. A continuación, en febrero de 1892, se aprobó extender las obras al tramo del camino Nuevo del Grao entre las vías del ferrocarril a Tarragona y la calle Mayor del Grao. ${ }^{32}$ En abril, la colocación de las vías fue adjudicada a Antonio Mellado Montesinos y D. G. Vranken, ingeniero de la compañía Demerbé. Completada la instalación en el mes de octubre, se procedió a la reconstrucción de los pasos adoquinados destruidos por las obras. ${ }^{33}$

Los beneficios derivados de la instalación de los carriles metálicos en el camino Nuevo del Grao hicieron que se extendiera a otras vías. En octubre de 1895 se aprobó su colocación en la bajada del puente del Mar frente a San Juan de Ribera; en noviembre de 1896, en la caída desde este puente hacia el camino de Monteolivete; en febrero de 1900, en la ronda exterior, desde el puente de San José hasta el camino Nuevo del Grao; y en diciembre de 1905, para el resto de rondas y el camino de Tránsitos de Consumos. ${ }^{34}$ En abril de 1908, ante la previsible extensión a otros caminos, la Comisión de Caminos y Policía Rural aconsejó la elección del sistema Gravenhorst de instalación, que fue aceptado en febrero de 1909 frente al modelo de la compañía alemana Phoenix..$^{35}$ Las obras en los caminos de Monteolivete y de Tránsitos de Consumos y el puente de Nazaret acabaron a finales de $1912 .{ }^{36}$ Quince años antes, el ayuntamiento ya había emitido un voto de gracias a Casimiro Meseguer por el éxito de su propuesta. ${ }^{37}$

La vía diseñada por Casimiro Meseguer contemplaba un carril en E puesto en horizontal en el que se usaba como banda de rodadura el extremo más largo. La compañía Demerbé lo fabricó uniendo dos carriles de $10 \mathrm{~m}$. con forma de $\mathrm{U}$ mediante pernos con tuerca y contratuerca colocados a lo largo del nervio central del carril. Las planchas resultantes tenían una anchura de 2,20 m. y una altura o profundidad de $132 \mathrm{~cm}$. (Figura 4). Los carriles se unían entre sí con bridas interiores y se atirantaban con riostras planas con entalladuras. Estos carriles eran capaces de soportar un peso de $4 \mathrm{Tm}$. por rueda y estaban reforzados con cuñas de acero hincadas a golpe de mazo y adoquines colocados a tizón. Según calculaba Meseguer en un informe de 1897, la instalación de las vías metálicas en 1892 había supuesto un ahorro para el ayuntamiento de más de 30.000 pesetas anuales, quedando amortizado su coste hacia 1902. Una buen inversión, teniendo en cuentas que la vida útil de estas vías rondaría los 25 ó 30 años. ${ }^{38}$

Figura 4. Dibujo de la vía metálica diseñada por Casimiro Meseguer, realizado en colaboración con el ingeniero municipal Vicente Pichó, 1911

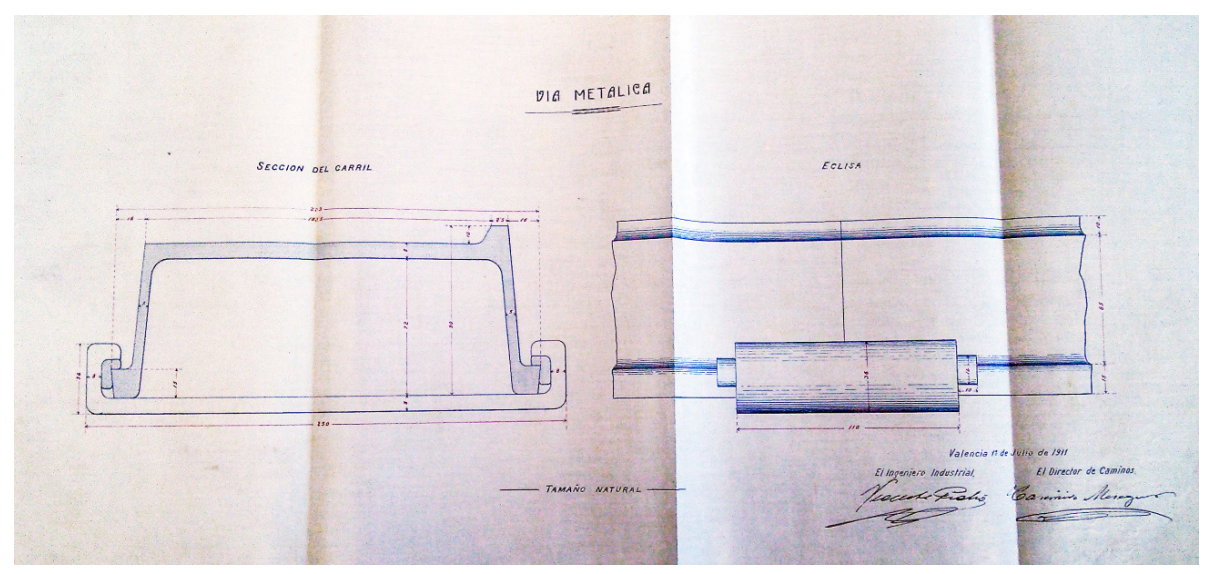

Fuente: Archivo Histórico Municipal de Valencia

\section{Camino-paseo Valencia al Mar (1888)}

El camino-paseo de Valencia al Mar fue proyectado por Casimiro Meseguer con el objetivo de dotar a la ciudad con una vía alternativa a las playas del norte que ayudara a descongestionar el camino Nuevo

32 AHMV: Libro de Actas, 1 y 22/VI y 14 y 28/IX/1891.

33 AHMV: Libro de Actas, 4 y 11/IV y 24/X/1892.

34 AHMV: Libro de Actas, 17/X/1895, 9/XI/1896; 12/II/1900; y 4/XII/1905.

35 AHMV: Libro de Actas, 6/IV/1908 y 8/II/1909.

36 AHMV: Fomento. Policía Rural, Rondas y Caminos, Subclase A, Caja 8

37 AHMV: Libro de Actas, 26/VII y 9/VIII/1897.

38 AHMV: Personal. Paseos y Caminos, 24/VII/1897. 
del Grao, saturado por el tráfico comercial hacia el puerto. Aunque fue incluido en el plan municipal de caminos aprobado por el Gobernador Civil en enero de 1883, con la denominación de Camino Paseo desde la Alameda hasta la playa del Cabañal, la primera presentación de este proyecto no se produjo hasta enero de $1888 .{ }^{39}$ Fue aprobado finalmente en junio de 1893 y declarado de utilidad pública por el Congreso de los Diputados un mes más tarde. La defensa del proyecto en Madrid fue realizada por el diputado e ingeniero de caminos Luis Page Blake, elegido por la circunscripción de Valencia (distrito de Requena) entre 1893 y $1896 .^{40}$

La propuesta definitiva fue presentada en septiembre de 1895 y elevada al Gobernador Civil, una vez superado el proceso de exposición pública y presentación de alegaciones, en mayo de $1896 .{ }^{41}$ Ante la imposibilidad de ponerlo en marcha, en 1898 se formó una comisión mixta con miembros de las áreas municipales de Caminos y Hacienda. Esta comisión presentó las bases del concurso que debía materializar el proyecto en agosto de 1899, pero los trabajos no terminaron de arrancar a causa de la lentitud del proceso de expropiación de las más de 400 hanegadas de huerta afectadas. ${ }^{42}$ En los años siguientes, lo único relevante fue la cesión de terrenos para la construcción de la Facultad de Medicina en agosto de 1906 y la convocatoria de un nuevo concurso de ideas a mediados de $1907 .{ }^{43}$ No fue hasta 1926, once años después de la muerte de Casimiro Meseguer, cuando el general Miguel Primo de Rivera puso la primera piedra de la actual avenida.

Figura 5. Plano de las principales vías de la ciudad de Valencia. Casimiro Meseguer, 1899

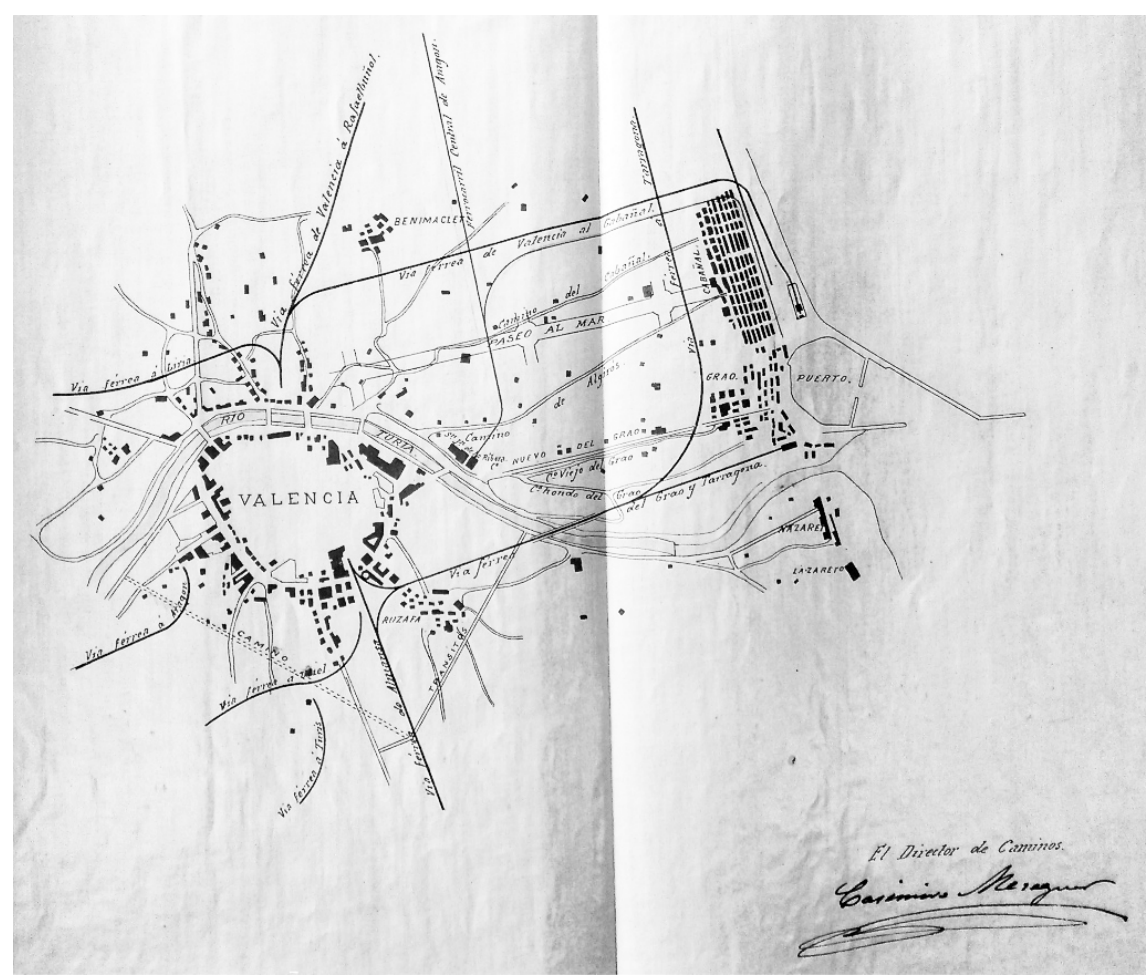

Fuente: Archivo Histórico Municipal de Valencia

El proyecto de Casimiro Meseguer, diferente del finalmente ejecutado, tomaba como referente la reforma ya efectuada en el paseo de la Alameda: un eje absolutamente rectilíneo en el que sobresalían una calzada central con dos andenes arbolados a ambos lados y varias plazas situadas en la intersección con

39 AHMV: Libro de Actas y Documentos, 27 y 31/1/1883; y Libro de Actas de la Comisión de Caminos, Paseos y Policía Rural, $20 / \mathrm{I} / 1888$. 40 AHMV: Libro de Actas, 26/VI y 17/VII/1893. Datos del diputado Luis Page Blake en el Archivo del Congreso de los Diputados de Madrid: Documentación Electoral, 107, n 53. La defensa de Page del 16/VI/1893 y la declaración de utilidad pública del paseo del 18/ VII/1893, en Diario de Sesiones del Congreso de los Diputados, 1893, Madrid. Apéndice $14^{\circ}$ al número 90 y Apéndice $19^{\circ}$ al número 52 , respectivamente.

41 AHMV: Libro de Actas, 12 y 19/IX/1895; y 11/V/1896.

42 AHMV: Libro de Actas, 27/VII/1898; 14 y 21/VIII/1899.

43 AHMV: Libro de Actas, 13/VIII y 22/X/1906; y 6/V/1907. Casimiro Meseguer fue el encargado de medir los terrenos cedidos por el ayuntamiento para la construcción de la Facultad de Medicina. 
otras vías para permitir los cambios de sentido (Figura 5). La anchura total del paseo era de $100 \mathrm{~m}$.: 25 $\mathrm{m}$. para el andén central; $20 \mathrm{~m}$. para los dos andenes peatonales laterales; $28 \mathrm{~m}$. para las dos franjas de jardinería y arbolado paralelas a estos últimos; $24 \mathrm{~m}$. para arroyos y aceras; y $3 \mathrm{~m}$. para las cunetas. $\mathrm{Al}$ margen de conectar la ciudad con su frente marítimo, el paseo aspiraba a reordenar los terrenos agrícolas situados entre los caminos de Algirós y del Cabañal siguiendo la tradición de la vivienda residencial suburbana. Un paseo-jardín que no pudo llevarse a cabo, en ese momento, por el elevado precio de la tierra y la preferencia de la burguesía valenciana por la vida en el ensanche (Piñón, 1988).

Se ha escrito que este proyecto pudo haberse inspirado en otro anterior del arquitecto Manuel Sorní para la construcción de un tranvía entre Valencia y los Poblados Marítimos (Boira, 2000; Piñón, 2000) y es muy posible que así fuese. Sorní no solo fue arquitecto municipal de Valencia entre 1854-1856 y 1868-1870, sino que en 1869 fue nombrado Director de Carreteras y Caminos Vecinales de la Diputación Provincial de Valencia, cargo que ocupó, al menos, hasta $1871 .{ }^{44}$ En esas fechas, Casimiro Meseguer estaba destinado en Valencia como Ayudante $4^{\circ}$ de Obras Públicas, de modo que no solo pudo acceder a la documentación municipal generada por Sorní al acceder a la Dirección de Caminos, sino que también pudo coincidir con él en alguna obra. Esta posibilidad no impide que Meseguer tuviera presente otras iniciativas de gran impacto en la ciudad. Entre ellas, y de manera singular, la construcción a partir de 1802 del camino Nuevo del Grao (Pingarrón, 1996-1997).

\section{Camino de Tránsitos de Consumos (1895)}

El camino de Tránsitos de Consumos fue creado para evitar que el tráfico de vehículos que no tenía como destino la ciudad de Valencia tuviera que atravesarla. Hay que recordar que, hasta principios del siglo XX, los carros con mercancías que entraban en ella tenían que pagar una tasa de consumos en los portazgos situados en los caminos de acceso. El nuevo camino constituía la tercera ronda de circunvalación en el margen derecho del río Turia (concéntrica a los anillos formados por el espacio de la antigua muralla y las grandes vías) y la primera en los espacios de nueva urbanización del margen izquierdo. Fue concebido en varias fases o secciones: la $1^{\text {a }}$ comprendía desde el cauce del río a la altura del camino de Monteolivete hasta la carretera de Casas del Campillo; la $2^{a}$, desde esta última hasta el cauce del río frente a Campanar; y la del Este, por último, desde la carretera de Ademuz hasta el camino Nuevo del Grao (Figura 6).

Figura 6. Plano de detalle del proyecto del camino de Tránsitos de Consumos. Casimiro Meseguer, 1903

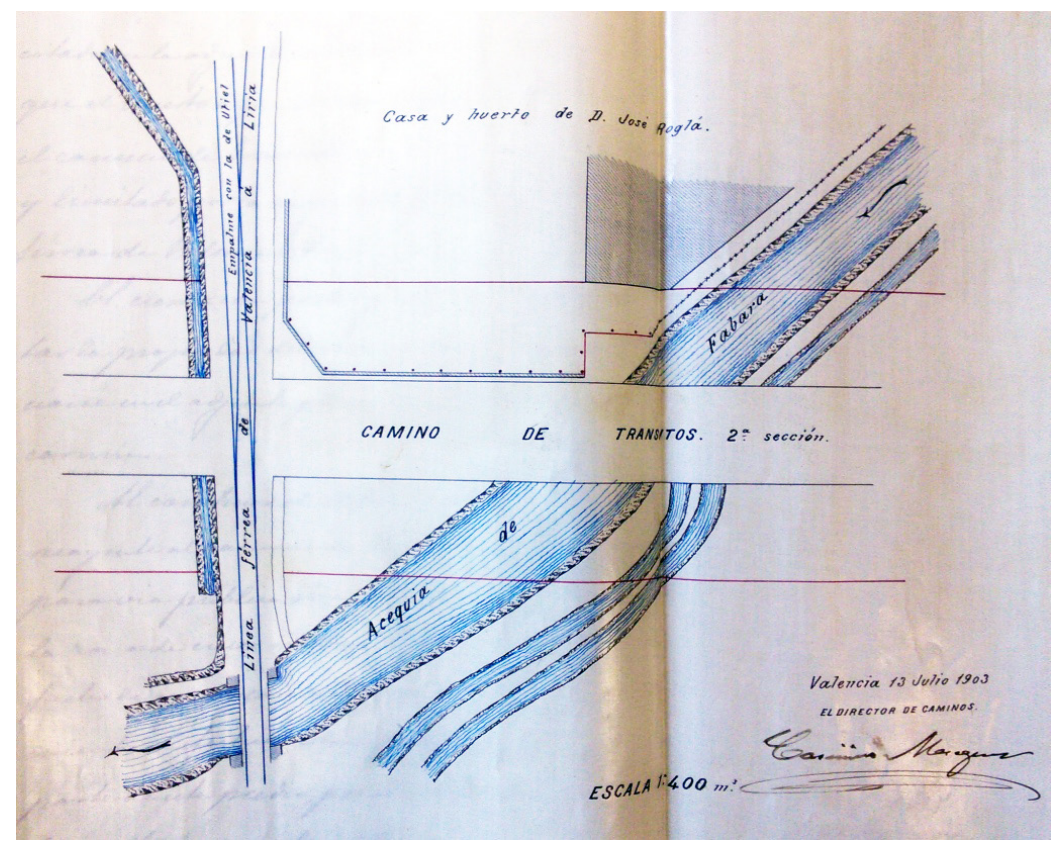

Fuente: Archivo Histórico Municipal de Valencia

\footnotetext{
44 Archivo General y Fotográfico de la Diputación Provincial de Valencia: Fomento. Carreteras y Caminos Vecinales, Personal de Carreteras, Caja 5. El nombramiento de Sorní se produjo el 13/1II/1869.
} 
El proyecto de las dos primeras secciones fue elevado al Gobernador Civil, a instancias de la Comisión de Caminos, Paseos y Policía Rural, en julio de 1895; el correspondiente a la sección del Este (luego, del Norte), en mayo de $1896 .{ }^{45}$ En abril de 1897 se aprobó el plano de las alineaciones a las que debía sujetarse la edificación a ambos lados del camino en sus dos primeras secciones y, seis meses después, el proyecto de reforma de sus rasantes. ${ }^{46}$ Sin embargo, las obras avanzaron con mucha lentitud debido, como en el camino-paseo Valencia al Mar, al costoso proceso de expropiaciones que generaban. Con el fin de agilizarlas, en noviembre de 1898 una comisión mixta que incluía a representantes de la Comisión de Consumos propuso una modificación, luego rechazada, del proyecto de la sección del Este que dejaba fuera los poblados de Orriols, Benimaclet y Campanar. La aprobación definitiva de este último por el Gobernador Civil no se produciría hasta octubre de $1900 .{ }^{47}$

Las dos primeras secciones del camino estaban acabadas a principios del siglo XX; la sección del Este no lo estuvo hasta 1911. En 1903 se aprobó el proyecto de las alineaciones que le afectaban y se cambió su denominación por la de sección del Norte. ${ }^{48} \mathrm{Al}$ año siguiente, se acordaron los pliegos de condiciones para la construcción de esta sección, desde la carretera de Madrid hasta el camino Nuevo del Grao, así como para su afirmado y el de la carretera de Ademuz. ${ }^{49}$ La liquidación de gastos para el tramo entre la carretera de Ademuz y el camino de Benimaclet se produjo en septiembre de 1908; la correspondiente al tramo entre los caminos de Benimaclet y Nuevo del Grao, en junio de 1910. La recepción definitiva de las obras tuvo lugar en mayo de 1911, pero la apertura completa del camino se retrasó hasta que estuvieron resueltos los cruces con paso a nivel de los ferrocarriles económicos de Valencia a Rafelbuñol y el Grao en los que Casimiro Meseguer venía trabajando desde 1905. ${ }^{50}$

\section{3. Óbito y reconocimiento público}

Casimiro Meseguer falleció el 1 de enero de 1915 en su domicilio de la calle de Los Ángeles, muy cerca del Mercado Central de Valencia, mientras desayunaba. Esa misma tarde, los diarios de la ciudad le reconocieron su gigantesca obra y se deshicieron en elogios hacia su persona. El cortejo fúnebre celebrado al día siguiente, desde la casa mortuoria hasta la iglesia de San Agustín, constituyó una enorme muestra de respeto. A su paso, en el ayuntamiento ondeaba la bandera a media asta y media puerta del portal permanecía cerrada en señal de luto. El ataúd era portado a hombros por peones camineros e iba precedido por el clero de los Santos Juanes con cruz alzada y por la práctica totalidad de la clase política de la ciudad. Su entierro en el Cementerio General fue, igualmente, un sentido acto de homenaje. ${ }^{51}$ Poco después, el pleno municipal acordó por unanimidad recoger en acta su consternación por el fallecimiento, se hizo cargo de los gastos del entierro y concedió a su viuda una pensión vitalicia de 1.500 pesetas. $^{52}$

\section{Discusión de resultados}

Casimiro Meseguer fue uno de los mayores protagonistas de la transformación urbanística que experimentó la ciudad de Valencia en la transición entre los siglos XIX y XX. Un hecho singular teniendo en cuenta que no formaba parte del grupo de arquitectos que dirigía los organismos encargados de vigilar dicho proceso. Formado como Ayudante de Obras Públicas, su ingente labor debe entenderse como la de un urbanista autodidacta, impelido por las obligaciones de su cargo a tomar decisiones que le sobrepasaban. La enorme complejidad de la zona extramuros, sobre la que se asentarían el ensanche y la urbanización paralela de terrenos intermunicipales, dejó en su manos la articulación de un espacio caótico sometido a dinámicas que únicamente eran posibles gracias a la red existente de sendas y caminos. El crecimiento demográfico y económico iniciado en la década de 1870 provocó la caducidad de esta red y obligó a un enorme ejercicio de reacomodación y ampliación de las vías que la formaban.

\footnotetext{
45 AHMV: Libro de Actas, 29/VII/1895 y 11/V/1896.

46 AHMV: Libro de Actas, 22/II y 25/X/1897. Los planos de las dos primeras secciones, en AHMV: Emilio Rieta, Alineaciones, Caja 8.

47 AHMV: Libro de Actas, 14/XI/1898; 14 y 21/VIII/1899; y 2/X/1900.

48 AHMV: Libro de Actas, 22/VI y 5/X/1903.

49 AHMV: Libro de Actas, 30/V y 8/VIII/1904.

50 AHMV: Libro de Actas, 3/IV/1905; 28/IX/1908, 20/VI/1910 y 1/V/1911.

51 Véanse las crónicas del 2/I/1915 publicadas en los periódicos La Correspondencia, El Pueblo, Las Provincias y El Diario de Valencia.

Consultadas en la Hemeroteca Digital de la Biblioteca Nacional de España; y la Biblioteca Virtual de Prensa Histórica del Ministerio de

Cultura y Deporte.

52 AHMV: Libros de Actas, 8/II/1915.
} 
El aumento de la circulación de vehículos mostró la insuficiencia de estas vías, así como el obstáculo que suponían para la instalación de infraestructuras emergentes como el alcantarillado, las conducciones de agua y electricidad o el propio tranvía. Casimiro Meseguer se ocupó del mantenimiento, la alineación y la conversión de estos caminos en vías urbanas. Una empresa encomiable, que atendió según todas las fuentes con suma dedicación. Ahora bien, ¿ ¿cómo pudo imaginar y emprender proyectos tan ambiciosos como los mencionados, tan alejados de sus obligaciones contractuales? Con toda probabilidad, por un efecto de capilaridad difícil de probar a partir de las fuentes existentes. Meseguer compartió estudios y trabajo de campo con algunos de los mejores ingenieros del estado y los mejores arquitectos valencianos de la época, a los que tuvo, respectivamente, como profesores en la Academia de Ayudantes de Obras Públicas (Lucio del Valle, Calixto de Santa Cruz, Juan López del Rivero, Práxedes Mateo Sagasta, Eduardo Echegaray, etc.) y como superiores en la Sección de Policía Urbana de la ciudad de Valencia (Joaquín $\mathrm{M}^{\mathrm{a}}$ Arnau, José Ma Manuel Cortina, Luis Ferreres, Sebastián Monleón, etc.).

De todos ellos debió adquirir las nociones sobre urbanismo que le permitieron acometer la planificación de los espacios extramuros que tenían encomendados. De sus ideas, la más original fue, sin duda, la instalación de planchas metálicas en los caminos más transitados de la ciudad como solución a los elevados costes de las subastas de piedra machacada. Se sabe que esta solución fue imitada en otras ciudades europeas y que no sería superada hasta la implantación de los asfaltos modernos (Esparza, 2017). También debe agradecerse a Casimiro Meseguer la construcción del camino de Tránsitos de Consumos como alternativa al tráfico intraurbano de vehículos. Esta propuesta sólo es comparable en su época con el paseo de Ronda que Pedro Núñez Granes imaginó (y no materializó) para la ciudad de Madrid en 1906. Los planos que recogían su proyecto de urbanización del extrarradio madrileño fueron presentados en 1909, catorce años más tarde que los evaluados por el ayuntamiento de Valencia en respuesta a la petición de Casimiro Meseguer.

Menos originales fueron los trabajos programados por Meseguer para la Alameda de Valencia y el paseo Valencia al Mar. El primero de ellos contaba con los precedentes firmados por los arquitectos valencianos Jorge Gisbert, Joaquín Tomás Belda y Carlos Spain y respondía al prototipo ilustrado de paseo burgués, consolidado en el siglo XIX gracias a la valoración positiva que habían adquirido los salones ajardinados (Santamaría, 1988). El segundo, por su parte, era contemporáneo del proyecto de ciudad lineal para Madrid de Arturo Soria (1886) y seguía la estela de los Public Walks de Londres, los bulevares de París, el Ringstrasse de Viena o el paseo de Recoletos-Castellana de Madrid delineado por Javier Mariátegui en 1833 (Sambricio, 1992; Roch, 1998 y 2000-2001). Ambos programas respondían a un geometrismo lineal que rompía con la cuadrícula del ensanche y buscaba resolver los problemas generados por la insuficiencia de los accesos al puerto de la ciudad (Delgado, 2010) y la implantación progresiva del tranvía (Giménez, 1999).

\section{Conclusiones}

Aunque se había iniciado con anterioridad, el crecimiento urbano de la ciudad de Valencia no se aceleró hasta el inicio del derribo de sus murallas medievales en 1865. Este proceso fue dirigido desde los negociados de Policía Urbana y Ensanche del ayuntamiento que encabezaban los arquitectos municipales, integrados más tarde en la Sección de Fomento. La Sección Facultativa de Policía Urbana y las direcciones anexas de Caminos y de Paseos, Arboledas y Jardines, en sus distintas denominaciones, fueron los organismos que materializaron las decisiones políticas en el día a día. En el interior del casco urbano se derribaron edificios que dificultaban el tránsito, se reordenaron calles y plazas y se abrieron nuevas vías de circulación. En el exterior, dominado todavía por los campos de cultivo, los aguazales y los eriales, se modificó y amplió la red de caminos, se abrieron otros nuevos y se pusieron las bases para la anexión de los poblados próximos (Ruzafa, Patraix, Benimaclet, Orriols, etc.).

Estos cambios, dilatados en el tiempo, cambiaron definitivamente la fisonomía de la ciudad. La Valencia que hoy conocemos fue el producto de un crecimiento tentacular que aprovechó la multitud de caminos existente en la zona extramuros. En sus márgenes se levantaron edificios, almacenes y naves industriales, hasta constituir una mancha urbana con visos de continuidad. La conexión y (re)alineación de estos caminos fue un desafío técnico que sólo pudo resolverse mediante la movilización de cientos de operarios (sobrestantes, auxiliares, delineantes, capataces, peones, etc.) y la inversión de ingentes cantidades de dinero provenientes de los presupuestos municipales. Al frente de todas estas gestiones 
(también de las económicas) estuvo durante cuarenta años Casimiro Meseguer Bonet, nombrado director municipal de Caminos en 1874 tras haberse formado como Ayudante de Obras Públicas en la escuela homónima de Madrid.

En esas cuatro décadas (1874-1914), Casimiro Meseguer no sólo se ocupó de las tares cotidianas que eran propias de su cargo, sino que prefiguró la Valencia del futuro. En su despacho fueron proyectados los ejes de crecimiento que todavía hoy condicionan la vida de la ciudad: la ronda de Tránsitos de Consumos, la avenida de Vicente Blasco Ibáñez, la conexión entre la avenida del Puerto y la Alameda o la autopista de El Saler. Fue un trabajador infatigable, inasequible al desaliento, al que la muerte sorprendió en plena actividad. Tres semanas antes había redactado su último informe, referido a un deslinde de terrenos junto a la acequia de Fabiana en la zona de Francos y Marjales, y sólo hacía diez días que había sido elegido para formar parte de la comisión que debía proceder al deslinde de todos los caminos y las parcelas municipales del término ${ }^{53}$ Era, en esos momentos, el funcionario más antiguo del ayuntamiento de Valencia. Un funcionario ejemplar, integérrimo, que no había disfrutado de un solo permiso o licencia de trabajo en cuarenta años de servicio. ${ }^{54}$

\section{Agradecimientos}

Este artículo está dedicado al Dr. Joan Francesc Mateu Bellés, maestro y amigo, en consideración a su extraordinaria carrera como docente e investigador.

\section{Referencias}

Arbaiza, S. (2014). Manuel Blanco y Cano: un arquitecto del siglo XIX. Academia, (116), 55-98.

Arnau, J. (Dir.) (2011). Fabular edificando: la obra de Cortina. Valencia: Generalitat Valenciana.

Arnau, J., Peiró, M.J. y Poyatos, J. (2008). La arquitectura de Arnau Miramón en la Valencia de 1900. Recuperado de http://www.quinoarnau.com/miramon/Valencia1900.pdf

Anguita, R. (1997). Ordenanza y Policía Urbana. Los orígenes de la reglamentación edificatoria en España (1750-1900). Granada: Universidad de Granada-Junta de Andalucía.

Anguita, R. (2001). Comisiones de Ornato Público, cuerpos de vigilancia de Policía Urbana y arquitectos municipales: el control de la actividad urbanística-edificatoria durante la génesis de la ciudad burguesa en España (1836-1898). En J.R. Cirici y M.D. Antigüedad (Coords.), Arquitectura y ciudad en España de 1845 a 1898 (pp. 225-230). Cádiz: Universidad de Cádiz.

Anónimo (1910). Los carriles en las carreteras. Revista Ilustrada de Banca, Ferrocarriles, Industria y Seguros, 420-422.

Benito, D. (1983). La arquitectura del eclecticismo en Valencia. Vertientes de la arquitectura valenciana entre 1875 y 1925. Valencia: Ajuntament de València.

Boira, J. V. (2000). Els origens del passeig de València al Mar: el projecte de Manuel Sorní de 1865. Cuadernos de Geografía, (67/68), 191-207.

Cabrera, I. (2015). Timoteo Calvo Ibarra (1799-1879). Un arquitecto valenciano durante el reinado de Isabel II. Archivo de Arte Valenciano, (96), 199-210.

Capel, H. (2009a). La historia, la ciudad y el futuro. Scripta Nova. Revista Electrónica de Geografía y Ciencias Sociales, (XIII), 307. Recuperado de https://revistes.ub.edu/index.php/ScriptaNova/article/ view/1613

Capel, H. (2009b). Geografía e historia urbana. En C. Delgado, L. Sazatornil y G. Rueda (Coords.), Historiografía sobre tipos y características históricas, artísticas y geográficas de las ciudades y pueblos de España (pp. 99-106). Santander: Ediciones TGD.

Cardesín, J. M. y Mirás, J. (2014). La historia urbana de España (siglos XVIII- XXI). En C. Lamela, J.M. Cardesín y M. García (Eds.), Dinámicas territoriales en España. Problemas y tendencias en la estructura y ordenación del territorio (pp. 21-51). Madrid: Biblioteca Nueva.

53 AHMV: Libro de Actas, 7 y 22/XII/1914.

54 AHMV: Fomento. Personal. Licencias, Asistencia y Hojas de Servicio, Caja 5. 
Casao, R. y García, M. (Eds.) (2009). Otra lectura de la reforma interior. En torno al proyecto de Luis Ferreres. Valencia: Ajuntament de València.

Delgado, C. (2010). Entre el puerto y la estación. La influencia de las infraestructuras de transporte en la morfología de las ciudades portuarias españolas (1848-1936). Scripta Nova. Revista Electrónica de Geografía y Ciencias Sociales, (XIV), 330. Recuperado de http://www.ub.edu/geocrit/sn/sn-330.htm

Delgado, C. (2016). Miradas sobre la ciudad desde la Geografía, la Historia y el Urbanismo. El estado de la cuestión a comienzos del siglo XXI. Ciudades, $(19,1), 117-142$. https://doi.org/10.24197/ ciudades.19.2016.117-142

Dirección General de Obras Públicas. (1859). Memoria sobre las Obras Públicas en España en fin del primer trimestre de 1859, presentada al Excmo. Sr. Ministro de Fomento (...). Madrid: Imprenta Nacional.

Dirección General de Obras Públicas. (1861). Memoria sobre el progreso de las Obras Públicas en los años de 1859 y 1860, presentada al Excmo. Sr. Ministro de Fomento por (...). Madrid: Imprenta Nacional.

Escuela de Ayudantes de Obras Públicas. (1868). Programas de las asignaturas que comprende la enseñanza en el curso de 1867 a 1868. Madrid: M. Rivadeneyra.

Faus, A. (2017). Planos de alineación de los antiguos caminos extramuros de la ciudad de Valencia (1860-1887). En L. Urteaga y F. Nadal (Eds.), Historia de la cartografía urbana en España: modelos y realizaciones (pp. 407-431). Madrid: Ministerio de Fomento, IGN, CNIG.

Faus, A. (2018a). La Sección Facultativa de Policía Urbana de la ciudad de Valencia. Evolución institucional (1844-1909). Saitabi, (68), 11-32.

Faus, A. (2018b). Quinientos planos de alineación de la ciudad de Valencia (1860-1909). Cuadernos de Geografía, (100), 121-148.

Esparza, D. (2017). Barcelona a ras de suelo. Barcelona: Universitat de Barcelona.

Fernández, G. (2011). Crecimiento urbano y modernización en España entre 1857 y 1900. Ería, (84-85), 5-46.

Gavara, J. J. (1994). El paseo de la Alameda de Valencia. Historia urbana de un espacio para la recreación pública (1644-1994). Ars Longa, (5), 147-157.

Giménez, V. (1999). Ferrocarriles y tranvías. El inicio de los ferrocarriles y tranvías de vía estrecha en Valencia. Valencia: Alfons el Magnànim.

Jaime, J. M. de (2013). Juan Mercader Gontier (Segorbe, 1824-¿1872?). Arquitecto, catedrático y director de la Escuela Industrial de Valencia. Segorbe: Fundación Mutua Segorbina.

Mendoza, J. (2011a). Las ciudades españolas a finales del siglo XIX: la visión de los técnicos. Ciudad y territorio, (169-170), 131-152.

Mendoza, J. (2011b). La ciudad: teoría y prácticas en la ciudad burguesa. En Silva, M. Técnica e ingeniería en España (VI), 741-787. Zaragoza: Real Academia de Ingeniería, Institución Fernando el Católico, Prensas Universitarias de Zaragoza.

Ministerio de Fomento. (1882). Escalafón del Cuerpo de Ayudantes de Obras Públicas, ratificado a $1^{\circ}$ de enero de 1882. Madrid: Manuel Minuesa de los Ríos.

Ministerio de Fomento. (1893). Escalafones de los cuerpos de Ingenieros de Caminos, Canales y Puertos, de Ayudantes y Sobrestantes de Obras Públicas. Madrid: Viuda de M. Minuesa de los Ríos.

Miño, L. (2003). El empleo del método de la historia en la investigación urbana. Anuario de la Universidad Internacional SEK, (8), 269- 284.

Muñoz, M. J. (2011). Los orígenes del trazado del paseo de la Castellana. Anales del Instituto de Estudios Madrileños (LI), 241-260.

Navascués, A. de y Pinillos, J. (1892). Manual administrativo personal de Obras Públicas (...) II. Ayudantes de Obras Públicas. Madrid: Manuel Minuesa de los Ríos.

Pingarrón, F. (1996-1997). El expediente municipal para la apertura del nuevo camino del Grao de Valencia (1787-1790). Ars Longa, (7-8), 111-124.

Piñón, J. L. (1988). Razones y sinrazones del paseo de Valencia al Mar de Casimiro Meseguer. En Serrano, A. (Coord.), I Congrés d'Història de la ciutat de València (II, 1.3.). Valencia: Ajuntament de València. 
Piñón, J. L. (2000). Conjeturas sobre los orígenes del paseo de Valencia al Mar. En S. Dauksis y F. Taberner (Eds.), Historia de la Ciudad. Recorrido histórico por la arquitectura y el urbanismo de la ciudad de Valencia (I) (pp. 147-161). Valencia: ICARO-COACV.

Ramos, D. (2007). La creación de la Escuela de Obras Públicas de Madrid. Cimbra, (373), 8-23.

Sanchis, E. (1896). El camino del Grao de Valencia. Revista de Obras Públicas-Boletín, (43), 78-80.

Sanchis, E. (1897). Carriles en las carreteras. Revista de Obras Públicas-Boletín, (44),420-422, 617-619 y 647-648.

Sanchis Guarner, M. (1972). La ciutat de València. Sintesi d'Història i de Geografia Urbana. Valencia: Cercle de Belles Arts.

Santamaría, M. T. (1988). La Alameda de Valencia. Prolongación y mejora del paseo en la segunda mitad del siglo XIX. Los proyectos de Joaquín Belda (1861), Carlos Spain (1862) y Casimiro Meseguer (1875 y 1877). En A. Serrano (Coord.), I Congrés d'Història de la ciutat de València (II), 3.3. Valencia: Ajuntament de València.

Settier, A. (1912). Las carreteras destruidas. Madrid Científico, (757), 686-688.

Taberner, F. (Ed.). (2000-2016). Historia de la Ciudad. Recorrido histórico por la arquitectura y el urbanismo de la ciudad de Valencia. Valencia: ICARO-COACV.

Teixidor, $\mathrm{M}^{\mathrm{a}} \mathrm{J}$. (1982). València. La construcció d’una ciutat. Valencia: Institució Alfons el Magnànim.

Terán, F. (1996). Evolución del planeamiento urbanístico (1846-1996). Ciudad y Territorio. Estudios Territoriales, (XXVIII, 107-108), 167-184.

Terán, F. de (1999). Historia del urbanismo en España. Vol. III. Siglos XIX y XX. Madrid: Cátedra.

Roch, F. (1998). Mirando hacia atrás: la Ciudad Jardín cien años después. Ciudad y Territorio. Estudios Territoriales, (XXX, 116), 449-474.

Roch, F. (2000-2001). La Ciudad Jardín, la urbanidad revisitada. Ciudades. Revista del Instituto Universitario de Urbanística de la Universidad de Valladolid, (6), 21-33.

Sambricio, C. (1992). De la ciudad lineal a la ciudad jardín. Sobre la difusión en España de los supuestos urbanísticos a comienzos del siglo. Ciudad y Territorio. Estudios Territoriales, (94), 147-159.

Straszewicz, L. (1981). Papel del geógrafo en las investigaciones del espacio urbano. Geographicalia, (9), $111-116$ 